\title{
Detecting water stress effects on fruit quality in orchards with time-series PRI airborne imagery
}

\author{
L. Suárez ${ }^{\text {a }}$ P.J. Zarco-Tejada a,*, V. González-Dugo a , J.A.J. Berni a , R. Sagardoy ${ }^{\text {b }}$, F. Morales ${ }^{\text {b }}$, E. Fereres ${ }^{\text {a,c }}$ \\ a Instituto de Agricultura Sostenible (IAS), Consejo Superior de Investigaciones Científicas (CSIC), Alameda del Obispo, s/n, 14004, Córdoba, Spain \\ b Department of Plant Nutrition, Experimental Station of Aula Dei, CSIC, Apdo 13034, 50080, Zaragoza, Spain \\ c Department of Agronomy, University of Cordoba, Campus Universitario de Rabanales, 14014, Córdoba, Spain
}

\section{A R T I C L E I N F O}

\section{Article history:}

Received 16 June 2009

Received in revised form 8 September 2009

Accepted 12 September 2009

\section{Keywords:}

Photochemical Reflectance Index (PRI)

EPS

Water stress

Fruit quality

TSS/TA

Multispectral remote sensing

Thermal

\begin{abstract}
A B S T R A C T
A methodology for the assessment of fruit quality in crops subjected to different irrigation regimes is presented. High spatial resolution multispectral and thermal airborne imagery were used to monitor crown temperature and the Photochemical Reflectance Index (PRI) over three commercial orchards comprising peach, nectarine and orange fruit trees during 2008. Irrigation regimes included sustained and regulated deficit irrigation strategies, leading to high variability of fruit quality at harvest. Stem water potential was used to monitor individual tree water status on each study site. Leaf samples were collected for destructive sampling of xanthophyll pigments to assess the relationship between the xanthophyll epoxidation state (EPS) and PRI at leaf and airborne-canopy level. At harvest, fruit size, Total Soluble Solids (TSS) and Tritatable Acidity (TA) were measured to characterize fruit quality. A statistically significant relationship between EPS and PRI was found at the leaf $\left(r^{2}=0.81\right)$ and canopy level $\left(r^{2}=0.41\right)$. Airborne-derived crown PRI calculated from the imagery acquired during the fruit growth was related to the ratio of the total soluble solids normalized by the tritatable acidity (TSS/TA), an indicator of fruit quality measured on the same trees, yielding a coefficient of determination of $r^{2}=0.50$. The relationship between the integral of PRI time-series and TSS/TA yielded a coefficient of determination of $r^{2}=0.72$ (peach) and $r^{2}=0.61$ (nectarines). On the contrary, the relation between TSS/TA and the time-series of crown thermal imagery was very weak $\left(r^{2}=0.21\right.$ and 0.25 respectively). These results suggest that a physiological remote sensing indicator related to photosynthesis, such as PRI, is more appropriate for fruit quality assessment than crown temperature, the established method of water stress detection, which is more related to crown transpiration. A radiative transfer modelling study was conducted to assess the potential validity of this methodology for fruit quality assessment when using medium spatial resolution imagery. The analysis shows important effects of soil and shadows on the PRI vs EPS relationship used for fruit quality assessment if non-pure crown reflectance was extracted from the imagery.
\end{abstract}

(C) 2009 Elsevier Inc. All rights reserved.

\section{Introduction}

Twenty-five years ago, thermal information was chosen for the remote sensing of water stress in crops (Jackson et al., 1981; Idso, 1982a,b) because the spectral vegetation indices that existed at that time were not nearly as sensitive to water deficits as those derived from canopy temperature (Jackson et al., 1983). Thermal remote sensing of water stress was first performed using spectrometers at ground level (Idso et al., 1981; Jackson et al., 1977, 1981), but other approaches have been developed more recently. These included the use of airborne thermal imagery (Cohen et al., 2005; Leinonen \& Jones, 2004; Sepulcre-Cantó et al., 2007) and satellite thermal information in combination with $3 \mathrm{D}$ radiative transfer models to understand the

\footnotetext{
* Corresponding author. Tel.: +34 957499 280, +34 676954 937; fax: +34957 499 252.

E-mail address: pzarco@ias.csic.es (P.J. Zarco-Tejada).

URL: http://quantalab.ias.csic.es (P.J. Zarco-Tejada).
}

effects of scene thermal components on large ASTER pixels (SepulcreCantó et al., 2009). Notwithstanding the advances in thermal detection, the visible part of the spectrum has also been useful for pre-visual water stress detection based on indices that use bands located at specific wavelengths where photosynthetic pigments are affected by stress condition. This is the case of the Photochemical Reflectance Index (PRI) (Gamon et al., 1992) that has been proposed to assess vegetation water stress based on xanthophyll composition changes (Peguero-Pina et al., 2008; Suárez et al., 2008, 2009; Thenot et al., 2002). The PRI was presented as an indicator of the epoxidation state of the xanthophylls pool or, what is the same, the proportion of violaxanthin that has been converted into zeaxanthin under stress conditions (Gamon et al., 1992). For water stress detection, PRI could be an alternative to thermal remote sensing, enabling the use of lowcost imaging sensors with high spatial resolution capabilities that are not possible in the thermal domain (Suárez et al., 2008, 2009).

In addition, the PRI is an index that was first formulated as an indicator of photosynthetic efficiency, but is also an indicator of 
photosynthesis rate through light use efficiency (Asner et al., 2005; Drolet et al., 2005; Fuentes et al., 2006; Guo \& Trotter, 2004; Nakaji et al., 2006; Nichol et al., 2000, 2002; Serrano \& Peñuelas, 2005; Sims et al., 2006; Strachan et al., 2002; Trotter et al., 2002) and through chlorophyll fluorescence (Dobrowsky et al., 2005; Evain et al., 2004; Nichol et al., 2006). Therefore, PRI in addition to being a water stress indicator, is also directly related to several physiological processes involved in the photosynthetic system.

The remote detection and monitoring of water stress is critical in many world areas where water scarcity is a major constraint to irrigated agriculture, and is forcing farmers to reduce irrigation water use via deficit irrigation (DI) (Fereres \& Soriano, 2007). One of the DI approaches is the regulated deficit irrigation (RDI), where water deficits are imposed only during the crop developmental stages that are the least sensitive to water stress (Chalmers et al., 1981). This practice was originally proposed to control the vegetative vigour in high-density orchards to reduce production costs and to improve fruit quality. However, it also saves irrigation water, with the concomitant benefits of reduced drainage losses (Fereres \& Soriano, 2007). It has long been known that tree water deficits affect fruit quality parameters (Veihmeyer, 1927). However, when water deficits are imposed as in RDI, yield and fruit size are not affected (Girona, 2002), while some quality parameters such as total soluble sugars and total acidity increase (Crisosto et al., 1994; Girona et al., 2003; Mills et al., 1994). The responses to RDI are variable depending on the timing and severity of water deficits (Marsal \& Girona, 1997; Girona et al., 2003) which vary within a given orchard; thus the need for remote sensing tools that could assist in monitoring stress over entire orchards. Additionally, the changes in irrigation depths with time and the lack of uniformity in water application during the irrigation period emphasize the need for a methodology that would cover the entire season, integrating the shortterm variations in tree water status. One option would be to use an integrated measure over time of tree water status (Myers, 1988; Ginestar \& Castel, 1996). González-Altozano and Castel (1999) related the time integral of stem water potential with yield and fruit quality parameters in citrus. Baeza et al. (2007) attempted the same approach on vineyards, finding a correlation between a water stress-integral and final berry size, although not with sugar composition. Although the relationships between water stress and fruit quality has been widely studied, the conclusion is that there is a lack of reliable indicators that predict with precision final fruit quality, and therefore there is a need for further research concerning potential fruit quality indicators.

Remote sensing of fruit quality has been attempted by several means such as by determining the vigour or total leaf area in vineyards (Johnson et al., 2001, 2003; Lamb et al., 2004); by relating quality parameters in water-stressed mandarin trees to spectral changes in the red and green channels (Kriston-Vizi et al., 2008), and by using high spatial resolution airborne thermal imagery to outline relationships of olive fruit size, weight, and oil content against thermal water stress indicators (Sepulcre-Cantó et al., 2007).

In this work, the PRI has been used to assess fruit quality parameters in peach and orange orchards under various water regimes. A time-series of airborne PRI imagery over a peach and an orange orchard under different irrigation treatments were acquired and related to fruit quality at harvest. Furthermore, a 3D radiative transfer model was used to assess the applicability of this method to medium resolution PRI imagery for extended monitoring of crops at larger scales. For this purpose, simulations using different soil backgrounds were conducted and the output spectral information was evaluated at different spatial resolutions.

\section{Material and methods}

\subsection{Study sites}

The experimental areas are located in Western Andalucía, Spain, a region of Mediterranean climate characterized by warm and dry summers and cool and wet winters, with an average annual rainfall of over $550 \mathrm{~mm}$.

The first study site was located on a commercial peach orchard planted in 1990 in a $5 \times 3.3 \mathrm{~m}$ grid on a deep soil with moderately high water holding capacity and classified as Typic Xerofluvents in Cordoba, Spain $\left(37.5^{\circ} \mathrm{N}, 4.9^{\circ} \mathrm{W}\right)$ (Fig. 1a). Two experiments were carried out in this location. One experiment was conducted using a set of eight rows of nine peach trees (Prunus persica cv. "BabyGold 8"). Within that set, 18 trees were drip irrigated starting in mid May (end of Stage I of fruit growth and beginning of Stage II) at a rate that met the evapotranspiration (ET) requirements (full-irrigated treatment or control). Additionally, three different RDI treatments were applied to plots of 12 trees each, by varying the onset of re-irrigation as Stage III of fruit growth commenced, following uniform water deficits imposed in Stage II. The dates of onset of re-irrigation (at 160\% of ET) were 4 July, 11 July and $17 \mathrm{July,} \mathrm{respectively.} \mathrm{In} \mathrm{the} \mathrm{same} \mathrm{commercial} \mathrm{orchard,}$ another experiment was conducted on nectarine trees (Prunus persica cv. "Sweet Lady"). Five rows of 30 trees each were irrigated meeting the ET requirement (following the commercial orchard schedule), while another six rows of 30 trees each were subjected to an RDI regime that imposed water deficits until 30 June, the beginning of Stage III (Fig. 1b).

The second study site was located near Seville, Southern Spain $\left(37^{\circ} \mathrm{N}, 5.7^{\circ} \mathrm{W}\right.$ ), on an 82 ha commercial citrus orchard (Fig. 1c shows the subset where the experiment was established). The light-textured soil is classified as Rodoxeralf, with an approximate depth of $3 \mathrm{~m}$. The trees were planted in 1997 in a $7 \times 3 \mathrm{~m}$ pattern on a $\mathrm{N}-\mathrm{S}$ orientation. The experiment was a randomized block design with six replications, each individual plot composed of five rows of three orange trees (Citrus sinensis L. cv. "Navelina"). Three different drip irrigation treatments were applied:, i) the control, that followed the orchard schedule which is designed to meet ET requirements for maximum production; ii) an over-irrigated treatment that applied $137 \%$ of control; and iii) a DI treatment that applied $62 \%$ of control. Table 1 lists the treatments, irrigation periods and depths, harvest and imagery acquisition dates for each of the study sites.

\subsection{Field data}

From the beginning of June till harvest, stomatal conductance $(G)$ and stem water potential $(\Psi)$ were measured weekly at midday with a leaf porometer (model SC-1, Decagon Devices, Washington, DC, USA) and a pressure chamber (PWSC Model 3000, Soil Moisture Equipment Corp., California), respectively. For the first experimental site, measured $\Psi$ values for the three RDI treatments were normalized by dividing them into the control $\Psi$ values of the full-irrigated treatment.

Leaf spectral measurements of adaxial surfaces were taken with a leaf probe that was attached to a field spectrometer ASD measuring in the spectral range of $400-1100 \mathrm{~nm}$ with a $25^{\circ}$ field of view (FieldSpec Handheld Pro, ASD Inc., CO, USA). Measurements were taken on four leaves per crown, which were collected and immediately frozen in liquid nitrogen. For these, leaf spectral properties and indices were calculated to assess relationships with pigment concentrations determined after extraction through chromatography (see below).

Two square centimeters of leaf tissue were obtained with a cork borer from each of the four leaves per tree crown. The discs were frozen in liquid nitrogen in the field and later kept under $-20{ }^{\circ} \mathrm{C}$ in microfuge tubes. Each leaf disc set corresponding to each crown was ground in a mortar on ice with liquid nitrogen and acetone (in the presence of $\mathrm{Na}$ ascorbate) up to $5 \mathrm{ml}$. Then, the extract was filtered through a $0.45 \mu \mathrm{m}$ filter to separate vegetation residues and $\mathrm{Na}$ ascorbate and left in dark tubes at $-20^{\circ} \mathrm{C}$ for pigment analysis, as reported by Abadía and Abadía (1993). First, absorption at 470, 644.8 and $661.6 \mathrm{~nm}$ was measured with a spectrophotometer in order to derive chlorophyll $\mathrm{a}$ and $\mathrm{b}$, and total carotenoid concentrations as 
(a)

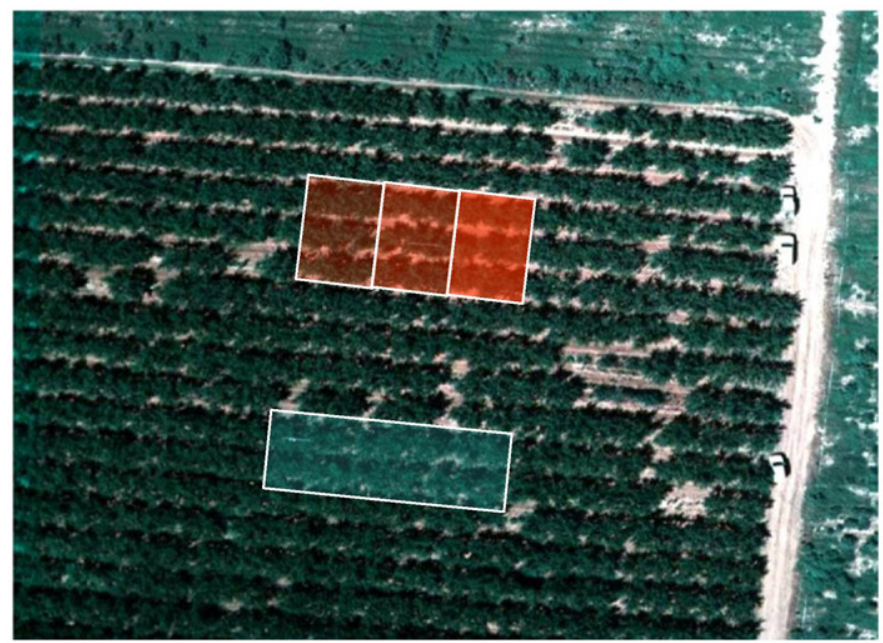

\begin{tabular}{|c|}
\hline $\begin{array}{c}\text { Irrigation } \\
\text { treatments }\end{array}$ \\
\hline RDI-1 \\
RDI-2 \\
RDI-3 \\
Fully-irrigated \\
\hline
\end{tabular}

(b)
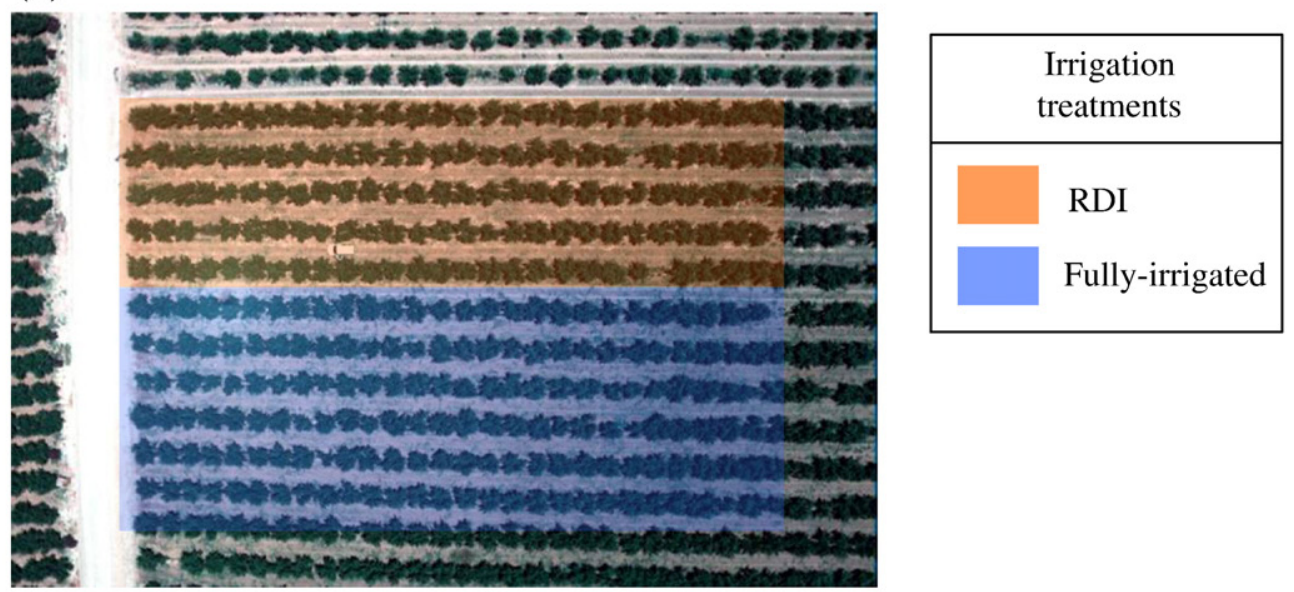

(c)
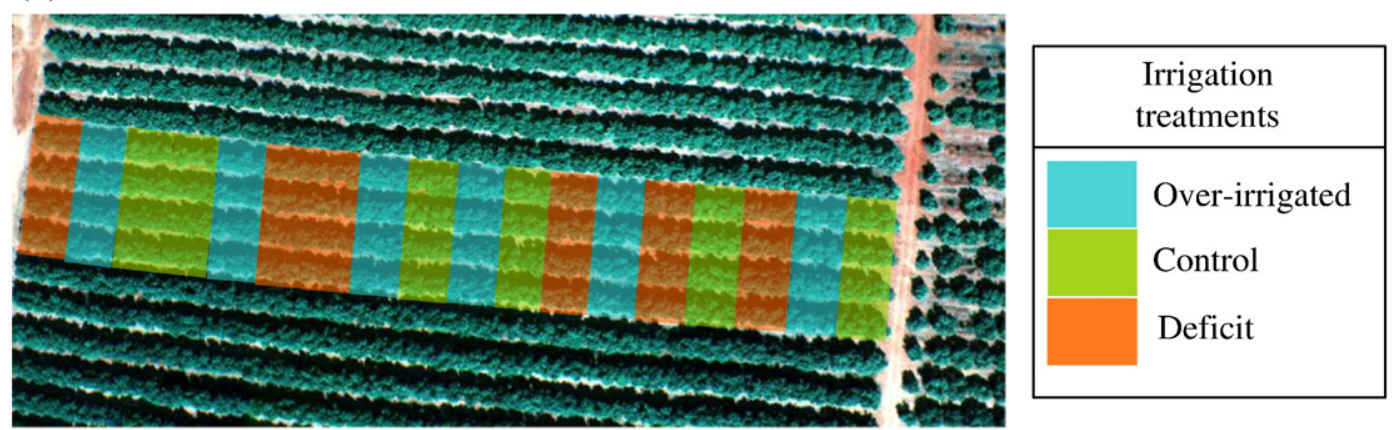

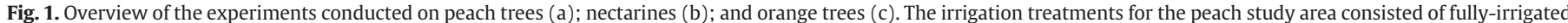

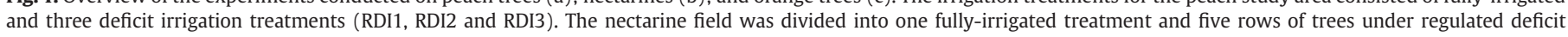
irrigation (RDI). In the orange tree experiment there were three different irrigation treatments: over-irrigated, control and deficit-irrigated.

described by Abadía and Abadía (1993). Samples were injected in a $100 \times 8 \mathrm{~mm}$ Waters Novapak C18 radial compression column $(4 \mu \mathrm{m}$ particle size) with a $20 \mu \mathrm{l}$ loop and mobile phases were pumped by a Waters M45 high pressure pump at a flow of $1.7 \mathrm{ml} / \mathrm{min}$ (Larbi et al., 2004).

In all three orchards, between 12 and 36 trees located in the centre of the irrigation treatments were monitored and harvested individually. All fruits from each tree were immediately weighted and their diameters measured. Later, eight fruits per tree were selected randomly for a physiochemical and organoleptic characterization of Total Soluble Solids (TSS) and Total Acidity (TA) used to calculate the ratio (TSS/TA). The combination of TSS and TA in the ratio TSS/TA is an indicator of both sweetness and fruit acidity, giving more information than TSS or TA separately (Crisosto et al., 2006). Fruit juice was obtained, filtered and measured with a pH meter (pH-Burette 24, Crison, Spain). To measure Titratable Acidity, $6 \mathrm{ml}$ of juice from each sample were mixed with $50 \mathrm{ml}$ of water and used for titrating with $0.1 \mathrm{~N} \mathrm{NaOH}$ to an end point of $\mathrm{pH}$ 8.2. The total volume of $\mathrm{NaOH}$ is 
Table 1

Summary of each study site, harvest, and imagery acquisition dates.

\begin{tabular}{|c|c|c|c|c|c|c|}
\hline Species & Treatments & Irrigation strategy & Withheld period & Irrigation dose & Harvest & Flights \\
\hline \multirow[t]{2}{*}{ Nectarine } & Control & Sustained & & $100 \%$ ET & \multirow[t]{3}{*}{ From $07 / 15$ to $08 / 07$} & 06/12, 06/19, 06/25, 07/01, 07/04, 07/17, 07/23, 07/29, \\
\hline & RDI & Regulated & $05 / 21$ to $06 / 30$ & $\begin{array}{l}\text { Re-watering:200\% ET, later: } \\
100 \% \text { ET }\end{array}$ & & $08 / 07,08 / 12$ \\
\hline \multirow[t]{4}{*}{ Peach } & Control & Sustained & & $80 \% \mathrm{ET}$ & & \\
\hline & RDI-1 & Regulated & $05 / 19$ to $07 / 04$ & $\begin{array}{l}\text { Re-watering: } 160 \% \text { ET, later: } \\
80 \% \text { ET }\end{array}$ & \multirow[t]{3}{*}{ From $08 / 06$ to $08 / 28$} & \multirow[t]{3}{*}{$\begin{array}{l}\text { 06/19, 06/25, 07/01, 07/04, 07/17, 07/23, 07/29, 08/07, } \\
08 / 12,08 / 21\end{array}$} \\
\hline & RDI-2 & Regulated & $05 / 19$ to $07 / 11$ & $\begin{array}{l}\text { Re-watering: } 160 \% \text { ET, later: } \\
80 \% \text { ET }\end{array}$ & & \\
\hline & RDI-3 & Regulated & $05 / 19$ to $07 / 18$ & $\begin{array}{l}\text { Re-watering: } 160 \% \text { ET, later: } \\
80 \% \text { ET }\end{array}$ & & \\
\hline \multirow[t]{3}{*}{ Orange } & Control & Sustained & & $100-130 \%$ ET & \multirow[t]{3}{*}{$11 / 03$} & \multirow[t]{3}{*}{$09 / 16$} \\
\hline & Deficit & Sustained & & $62 \%$ ET & & \\
\hline & $\begin{array}{l}\text { Over- } \\
\text { irrigated }\end{array}$ & Sustained & & $137 \%$ ET & & \\
\hline
\end{tabular}

The treatments under RDI had a "withheld period" (no irrigation) followed by a re-watering period until their stem water potential were equal to the control.

measured and used to calculate the Titratable Acidity using the Eq. (1).

$\%$ Acid $=\frac{\mathrm{ml}(\mathrm{NaOH}) \text { used } \times(0.1 \mathrm{~N} \mathrm{NaOH}) \times(\text { milliequivalent factor }) \times 100}{\text { grams of sample }}$

The milliequivalent factor is a coefficient dependant on the most predominant acid in the fruit. In the case of peach trees, malic acid is predominant and the milliequivalent factor is 0.067 . For orange trees, citric acid is predominant, with a milliequivalent factor of 0.064 . Soluble solids concentration (SSC\%, ${ }^{\circ} \mathrm{Brix}$ ) was determined in a small sample of fruit juice using a hand-held refractometer (Atago, ATC-1E, Japan).

Pigment concentrations were derived from the total area of the peaks in the chromatogram using previously determined calibration coefficients calculated by injecting pure pigments into the HPLC circuit. From the xanthophyll pigment concentrations of violaxanthin $(V)$, antheraxanthin $(A)$, and zeaxanthin $(Z)$, the epoxidation state (EPS) was calculated as $\left(V+0.5^{*} A\right) /(V+A+Z)$ (Thayer \& Björkman, 1990). The EPS was calculated from the leaf set corresponding to each crown and compared with the PRI calculated as (R570-R531)/ (R570 + R531) (Gamon et al., 1992), from the spectra measured in the field on the same four leaves sampled.

\subsection{Airborne imagery}

A 6-band multispectral camera (MCA-6, Tetracam, Inc., California, USA) was flown in the summer of 2008 at $150 \mathrm{~m}$ above the ground level using an unmanned aerial vehicle (UAV) (Berni et al., 2009), acquiring a time-series of 12 images on different dates from the two study sites. Eleven images were acquired on the commercial field covering the nectarine and peach experiments from the beginning of the Stage II of fruit growth (12th of June) till the end of harvest (21 August). In the orange orchard, the water status of the different irrigation treatments was kept constant. Hence, there was no need for characterizing the water stress over the whole fruit growing period, and a single image acquired on 16 September was used. The camera has six image sensors with $25 \mathrm{~mm}$ diameter bandpass filters of $10 \mathrm{~nm}$ FWHM (Andover Corporation, NH, USA). The image resolution is $1280 \times 1024$ pixels with 10 -bit radiometric resolution and optical focal length of $8.5 \mathrm{~mm}$, yielding a ground-based spatial resolution of $15 \mathrm{~cm}$ at $150 \mathrm{~m}$ altitude. The bandsets used in each of the study sites included those centered at 530 and $570 \mathrm{~nm}$ used to calculate the PRI index, as well as 550, 670, 700 and $800 \mathrm{~nm}$ to calculate the TCARI/ OSAVI index for chlorophyll content estimation (Haboudane et al., 2002), and the NDVI (Rouse et al., 1974), and the SR for LAI estimation. An overview of the spectral indices used in this study can be found in Table 2. Geometric calibration of airborne data was conducted as explained in Berni et al. (2009). The camera was radiometrically calibrated using coefficients derived from measurements made with a uniform calibration body (integrating sphere, CSTM-USS-2000C Uniform Source System, LabSphere, NH, USA) at four different levels of illumination and six different integration times. Radiance values were later converted to reflectance using total incoming irradiance simulated using sunphotometer (Microtops, Solar Light inc.) data taken in the field at the time of imagery acquisition.

A thermal camera (Thermovision A40M; FLIR, USA) was installed onboard the airborne platform. Its image resolution was $320 \times 240$ pixels and 16 bits of at-sensor calibrated radiance with a $40^{\circ}$ FOV lens, yielding $40 \mathrm{~cm}$ spatial resolution at $150 \mathrm{~m}$ altitude. The image sensor is a Focal Plane Array (FPA) based on uncooled microbolometers with a spectral range of $7.5-13 \mu \mathrm{m}$, yielding calibrated radiance in the range of 233-393 K. The methodology for obtaining surface temperature from radiance temperature by removing atmospheric effects using a single-channel atmospheric correction is explained in Berni et al. (2009).

As PRI is an index related to light use efficiency, the index was normalized with the incoming PAR over the time-series at the time of image acquisition, calculated as the integral of the irradiance in the visible region of the electromagnetic spectrum (range 400-700 nm). Thus, PRI/PAR values could be used to study the time-series over the stages II and III of fruit growth. Reflectance values were obtained for the six spectral bands for every single crown for the whole timeseries. The high spatial resolution allowed the identification of each

Table 2

Overview of the vegetation indices used in this study and their formulation, with $R_{\mathrm{x}}$ being the reflectance at $x \mathrm{~nm}$.

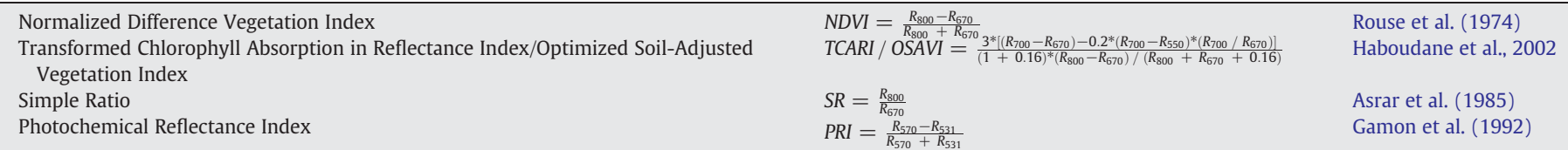


individual tree and the possibility of selecting pure sunlit vegetation pixels. The pixels at the edge of the crowns were not used to extract the spectral information. Additionally, individual crown temperature $\left(T_{\mathrm{c}}\right)$ was extracted from thermal imagery avoiding crown edge pixels and was normalized with air temperature $\left(T_{\mathrm{a}}\right)$ to use the value of $T_{\mathrm{c}}-T_{\mathrm{a}}$ for the analysis. The integral over time was calculated for five indices: PRI/PAR, $T_{\mathrm{c}}-T_{\mathrm{a}}$, NDVI, SR, and TCARI/OSAVI for the period from 19th of July to 7th of August when the harvest started. For indices having both negative and positive values, the minimum value found for each index along the whole period was used as a reference line to calculate the integral for all the trees, as explained in Myers (1988).

In order to study the effect of the spatial resolution on PRI, the aggregated reflectance including shadows, soil and crown components was extracted for each crown in all images acquired, and the integral calculated. For this purpose, regions of interest comprising each individual crown, and the adjacent soil were created and the spectral information extracted.

\subsection{Radiative transfer modelling}

The 3D Forest Light interaction radiative transfer model (FLIGHT, North, 1996) was used to investigate the application of this methodology to larger spatial resolution imagery, by assessing canopy aggregation effects on PRI. The FLIGHT model has been successfully used to simulate PRI in previous studies (Barton and North, 2001; Suárez et al., 2008, 2009). In this case, typical peach leaf spectral characteristics and tree structural parameters were inputs for simulating vegetation cover ranging from $10 \%$ to $100 \%$ on three different soil types. Typical peach leaf reflectance and transmittance spectra were simulated using PROSPECT model (Jacquemoud and Baret, 1990) for $N=1.6, C_{\mathrm{ab}}=40 \mu \mathrm{g} / \mathrm{cm}^{2}, C_{\mathrm{m}}=C_{\mathrm{w}}=0.015$ and $C_{\mathrm{s}}=0$. The input values of $N, C_{\mathrm{m}}, C_{\mathrm{w}}$, and $C_{\mathrm{s}}$ were found in previous literature on peach trees (Suárez et al., 2009), the input value for $C_{\mathrm{ab}}$ was defined as the average of the chlorophyll concentrations estimated by destructive methods. The canopy input parameters used were crown $\mathrm{LAI}=2.5, \mathrm{LAD}=$ spherical and leaf size $=0.02 \mathrm{~m}$. The solar geometry corresponded to mid July at 10:00 GMT in Cordoba, Spain $\left(\right.$ solar zenith $=23^{\circ}$ and solar azimuth $=124^{\circ}$ ). Fig. 2 represents the three generic soil spectra used (Fig. 2a) and three simulations conducted for dark soil and 30\% (Fig. 2b), 50\% (Fig. 2c), and $70 \%$ vegetation cover (Fig. $2 \mathrm{~d}$ ). From each simulation, crown reflectance and scene reflectance were extracted digitalizing regions of interest on the simulated scene image to calculate crown PRI and scene PRI, respectively. Crown PRI values were compared to scene PRI values in order to assess the effects caused by the spatial resolution on the index. One of the outputs of FLIGHT radiative transfer model is the percentage of each element: shadowed soil, sunlit soil, shadowed vegetation and sunlit vegetation in the whole simulated scene. Those percentages were used to assess the magnitude of the error when deriving EPS from an aggregated pixel of soil, shadows and vegetation as a function of the soil type. For this purpose, scenes with a vegetation cover of $50 \%$ were simulated using the soil spectra in Fig. 2. The aggregated pixel reflectance was calculated as the sum of the fractional covers of each element in the scene multiplied by its reflectance. The vegetation fractional cover was considered to be the sum of the fractional covers for sunlit and shadowed vegetation from the FLIGHT output. The aggregated pixel reflectance was calculated as the sum of the fractional covers of each element in the scene multiplied by its reflectance. The vegetation fractional cover was

(a)

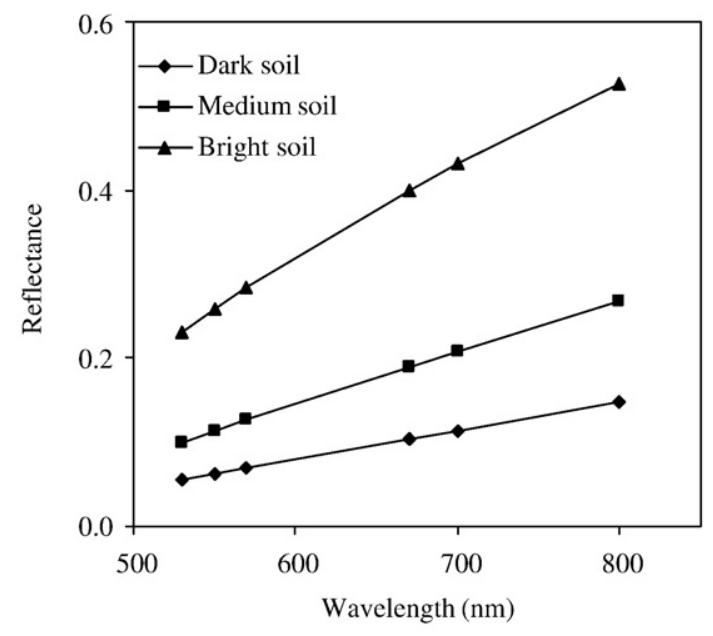

(b)

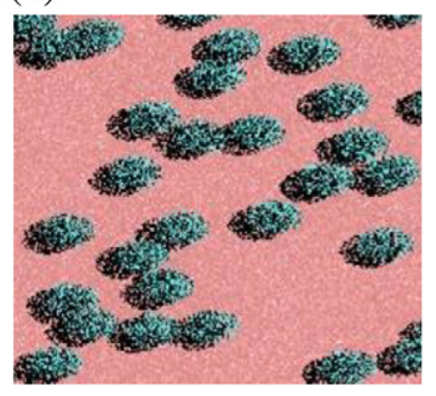

(c)

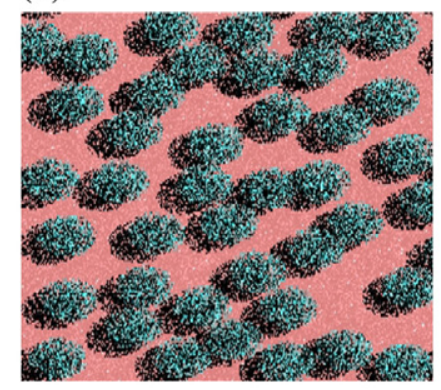

(d)

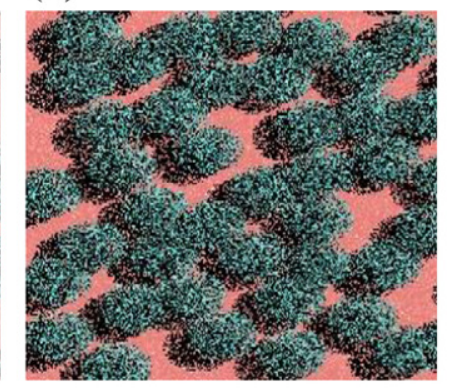

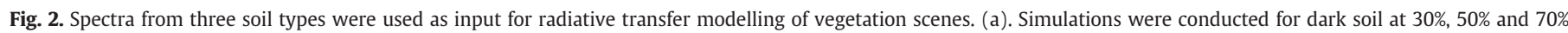
vegetation coverage (b, c and d, respectively). 
considered to be the sum of the fractional covers for sunlit and shadowed vegetation from the FLIGHT output. The aggregated scene reflectance was the result of using tree reflectance which corresponded to the vegetation fractional cover in the scene. Three different scenes were recreated per tree using three soil types. For each tree, the EPS value was compared to the aggregated PRI
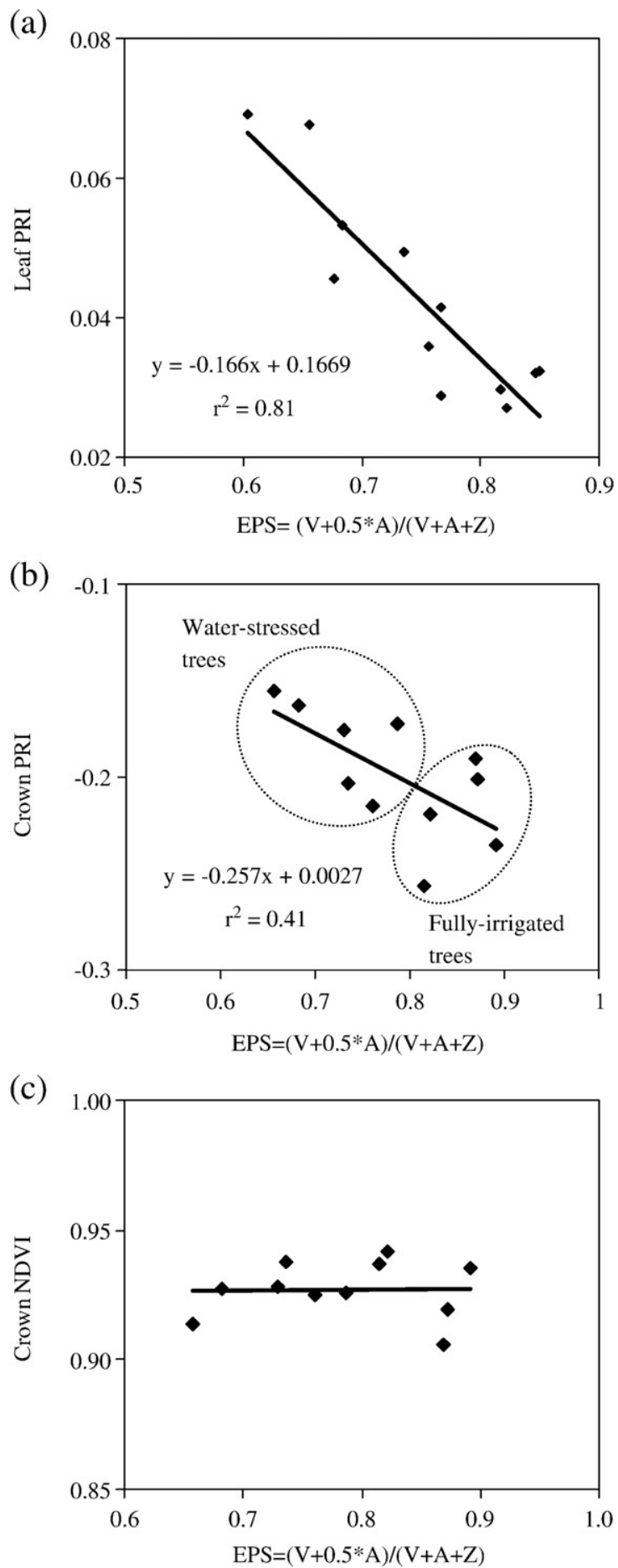

Fig. 3. (a) Relationship between the epoxidation state (EPS) calculated from xanthophyll pigment extraction and PRI from spectral measurements on the same leaves from a total of 12 tree crowns. Relationship between the EPS calculated from the averaged xanthophyll content of four leaves per crown and spectral indices extracted from imagery for the crowns: PRI index (b) and NDVI (c).

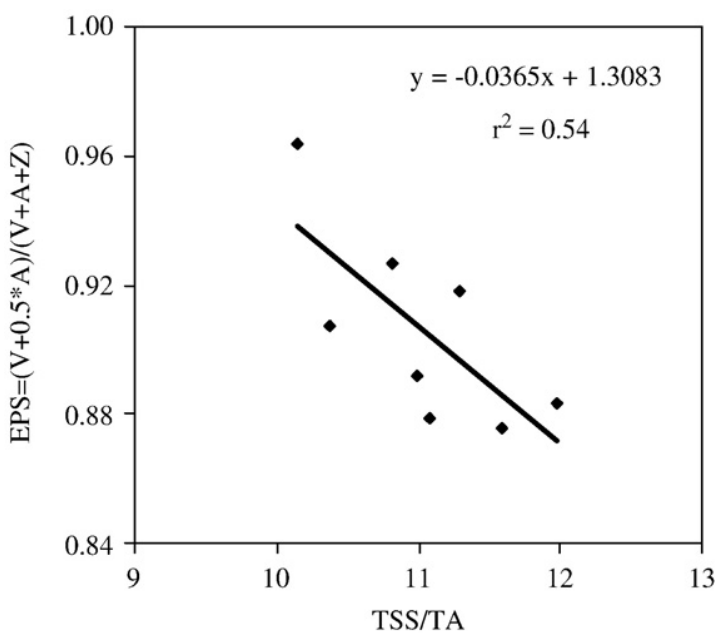

Fig. 4. Correlation between pre-harvest EPS in the nectarine orchard experiment and the fruit quality ratio, Total Soluble Solids/Tritatable Acidity (TSS/TA).

calculated from tree reflectance and the reflectance of the fractions of shadowed and sunlit soil.

\section{Results and discussion}

Fig. 3a shows that, at the leaf level, the EPS calculated from pigment determination methods was well correlated with leaf PRI calculated from the same leaves collected in the field. Leaves with higher EPS values, corresponding to a high concentration of the photosynthetic active pigment violaxanthin over the whole xanthophyll pool, and consequently less stressed, presented lower PRI values. Lower values of PRI are the consequence of lower absorption at $530 \mathrm{~nm}$ using the presented formulation of PRI corresponding to a lower concentration zeaxanthin, which is the xanthophyll pigment inhibiting photosynthesis (Gamon et al., 1992). At the crown level, the photon interaction with vegetation structure and the effect of leaf angle distribution result in lower PRI values as we can see in Fig. 3b and $c$. These figures depict the relationships obtained between EPS, crown PRI $\left(r^{2}=0.41\right)$, and crown NDVI $\left(r^{2}=0.15\right)$ extracted from the canopy images. The data shown on Fig. $3 b$ and c suggest that PRI changes are driven by physiological processes related to xanthophyll pigments and not by vegetation structure. At both leaf and canopy scales, PRI and chlorophyll a + b content were not correlated, yielding coefficients of determination of $r^{2}=0.04$ and $r^{2}=0.01$ respectively (data not shown), indicating that PRI changes were not driven by chlorophyll content differences. Several authors have previously found an inverse relationship between EPS and PRI (Filella et al.,

Table 3

Coefficients of determination $\left(r^{2}\right)$ in the orange experiment, between indices [PRI, $T$, NDVI, SR and TCARI/OSAVI] and post-harvest fruit quality parameters [TSS, Total Soluble Solids; TA, Tritatable Acidity; the ratio, TSS/TA; and the median of the fruit size].

\begin{tabular}{|c|c|c|c|c|c|}
\hline & & \multicolumn{4}{|c|}{ Orange } \\
\hline & & TSS & $\mathrm{TA}$ & $\begin{array}{l}\text { TSS/ } \\
\text { TA }\end{array}$ & $\begin{array}{l}\text { Fruit } \\
\text { size }\end{array}$ \\
\hline \multirow[t]{2}{*}{ Indices for water stress detection } & PRI & 0.17 & $0.50^{* *}$ & $0.50^{* *}$ & 0.11 \\
\hline & $T(\mathbf{K})$ & 0.00 & 0.01 & 0.00 & $0.47^{*}$ \\
\hline \multirow[t]{2}{*}{ Structural indices } & NDVI & $0.28^{*}$ & $0.33^{*}$ & 0.16 & $0.17^{*}$ \\
\hline & SR & $0.28^{*}$ & $0.34^{*}$ & 0.17 & $0.18^{*}$ \\
\hline Chlorophyll index & $\begin{array}{l}\text { TCARI/ } \\
\text { OSAVI }\end{array}$ & $0.24^{*}$ & 0.35 & 0.28 & 0.32 \\
\hline
\end{tabular}

Pearson's analysis.

** Correlation is significant at the 0.01 level (2-tailed) (In bold)

*Correlation is significant at the 0.05 level (2-tailed). 
(a)

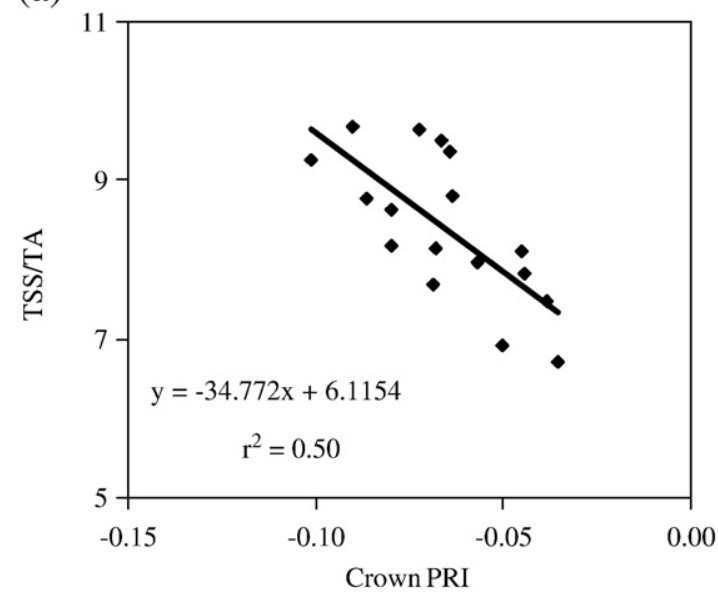

(c)

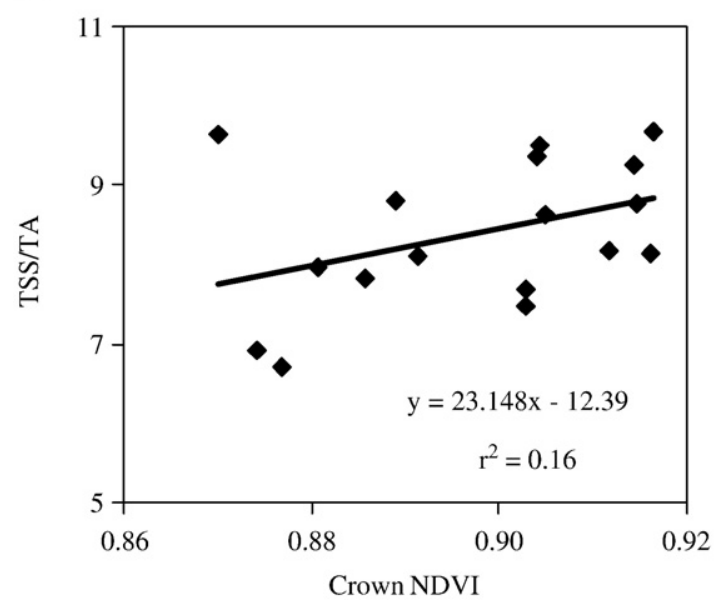

(b)

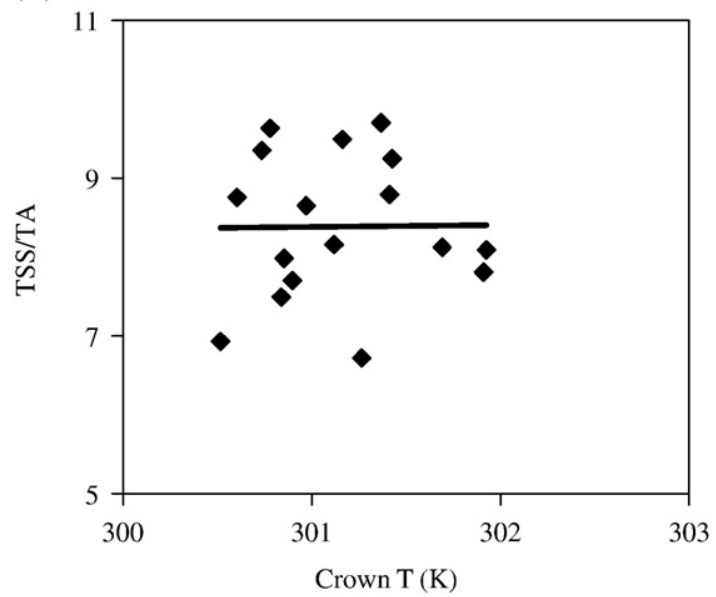

(d)

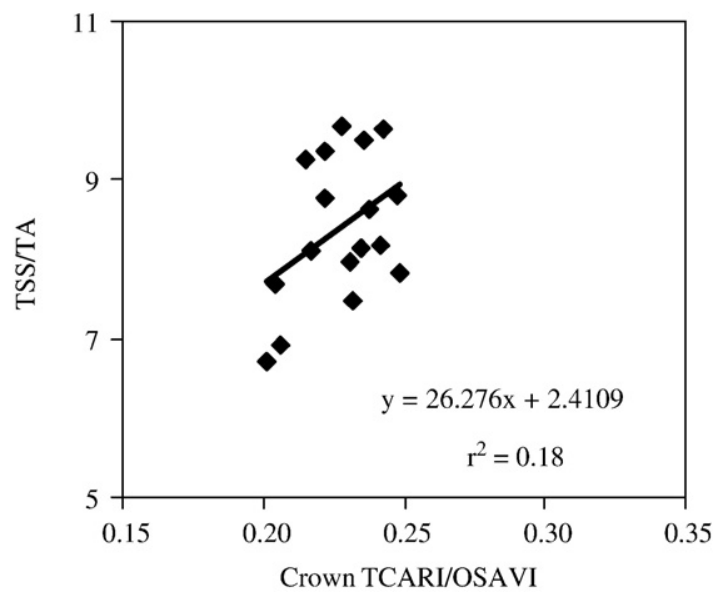

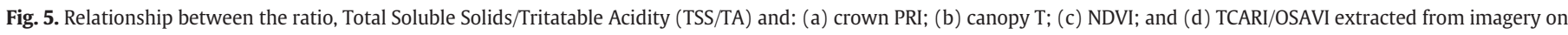
the orange orchard study area.

1996; Gamon et al., 1992, 1997; Guo et al., 2006; Nichol et al., 2006), as shown in Fig. 3b. The results in Fig. 3 demonstrate the link between PRI and the xanthophyll cycle in peach at both leaf and canopy scales.

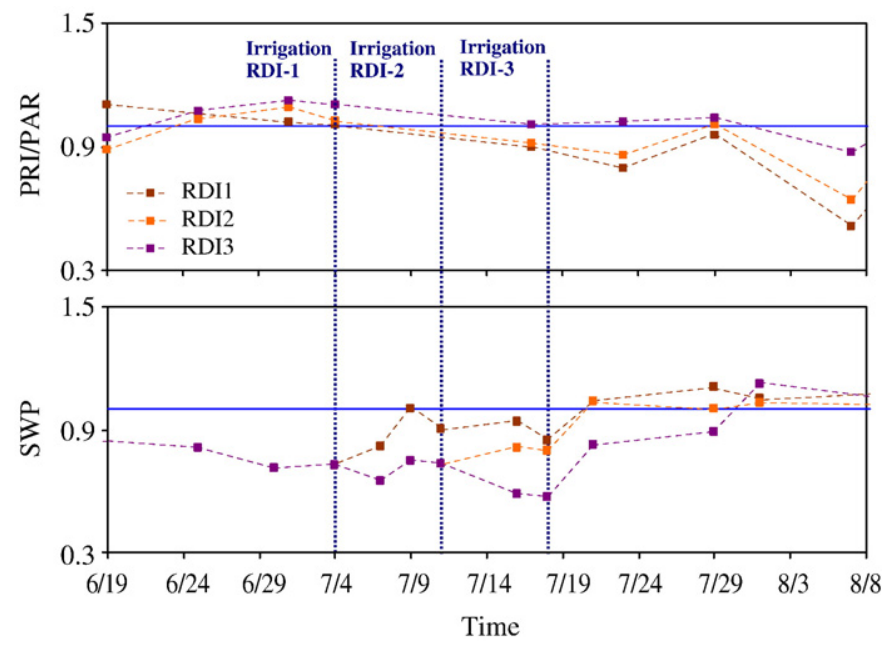

Fig. 6. Overview of the time-series for the peach deficit irrigation treatments normalized by the fully-irrigated treatment values of PRI/PAR and stem water potential (SWP) from the beginning of Stage II of fruit growth until harvest. I1, I2 and I3 correspond to the dates in which RDI1, RDI2 and RDI3 treatments were re-irrigated to recover from water stress.
The different irrigation treatments generated variability in fruit quality, as assessed by the TSS/TA ratio measured at harvest. The TSS/TA variability in the peach orchard with four irrigation treatments was greater than the TSS/TA variability found in the nectarine and orange orchards, where only one deficit irrigation treatment was applied. Fig. 4 shows the relationship between EPS at crown scale and TSS/TA

Table 4

Coefficients of determination $\left(r^{2}\right)$ for peach and nectarine between the time-series integral of indices [PRI/PAR, $T_{\mathrm{c}}-T_{\mathrm{a}}, \mathrm{NDVI}, \mathrm{SR}$ and TCARI/OSAVI] and the fruit quality parameters [TSS, Total Soluble Solids; TA, Tritatable Acidity; the ratio, TSS/TA and the median of the fruit size].

\begin{tabular}{|c|c|c|c|c|c|c|c|c|c|}
\hline & & \multicolumn{4}{|l|}{ Peach } & \multicolumn{4}{|c|}{ Nectarines } \\
\hline & & TSS & $\mathrm{TA}$ & $\begin{array}{l}\text { TSS/ } \\
\text { TA }\end{array}$ & $\begin{array}{l}\text { Fruit } \\
\text { size }\end{array}$ & TSS & $\mathrm{TA}$ & $\begin{array}{l}\text { TSS/ } \\
\text { TA }\end{array}$ & $\begin{array}{l}\text { Fruit } \\
\text { size }\end{array}$ \\
\hline $\begin{array}{l}\text { Indices for } \\
\text { water }\end{array}$ & $\int_{\text {PAR }) \mathrm{d} t}(\mathrm{PRI} /$ & 0.28 & $0.48^{*}$ & $0.72^{* *}$ & 0.01 & 0.05 & 0.22 & $0.61^{\text {** }}$ & $0.32^{*}$ \\
\hline $\begin{array}{l}\text { stress } \\
\text { detection }\end{array}$ & $\begin{array}{l}\int_{T_{\mathrm{a}}}\left(T_{\mathrm{c}}-\right. \\
T t\end{array}$ & 0.01 & 0.27 & 0.21 & 0.27 & 0.04 & 0.02 & 0.24 & 0.28 \\
\hline Structural & $\int(\mathrm{NDVI}) \mathrm{d} t$ & $0.60 *$ & 0.00 & $0.55^{* *}$ & 0.00 & 0.07 & 0.13 & 0.16 & 0.46 \\
\hline indices & $\int(\mathrm{SR}) \mathrm{d} t$ & 0.32 & $0.36^{*}$ & $0.62^{* *}$ & 0.00 & 0.15 & 0.03 & 0.03 & 0.13 \\
\hline $\begin{array}{l}\text { Chlorophyll } \\
\text { index }\end{array}$ & $\begin{array}{l}\int_{\text {OSAVI }}(\mathrm{TCARI} \mathrm{d} t \\
\end{array}$ & $0.55^{* *}$ & 0.05 & $0.38^{*}$ & 0.05 & 0.02 & 0.08 & 0.26 & 0.28 \\
\hline
\end{tabular}

Pearson's analysis.

** Correlation is significant at the 0.01 level (2-tailed) (In bold).

*Correlation is significant at the 0.05 level (2-tailed). 
(a)

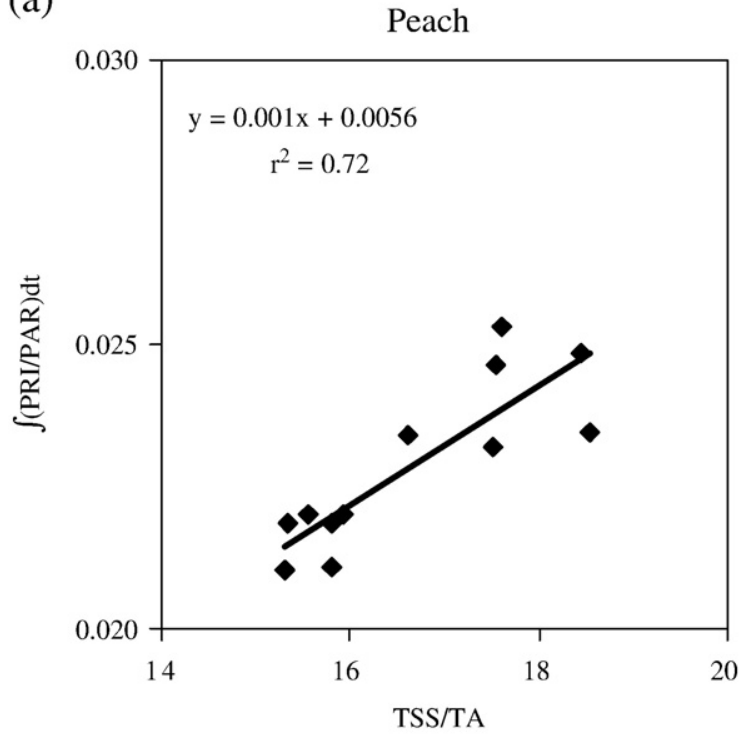

(c)

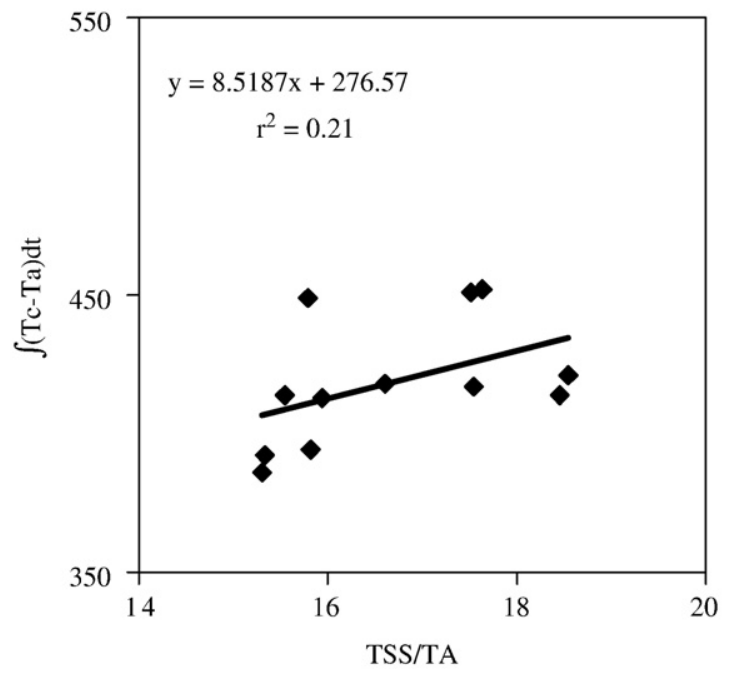

(b)

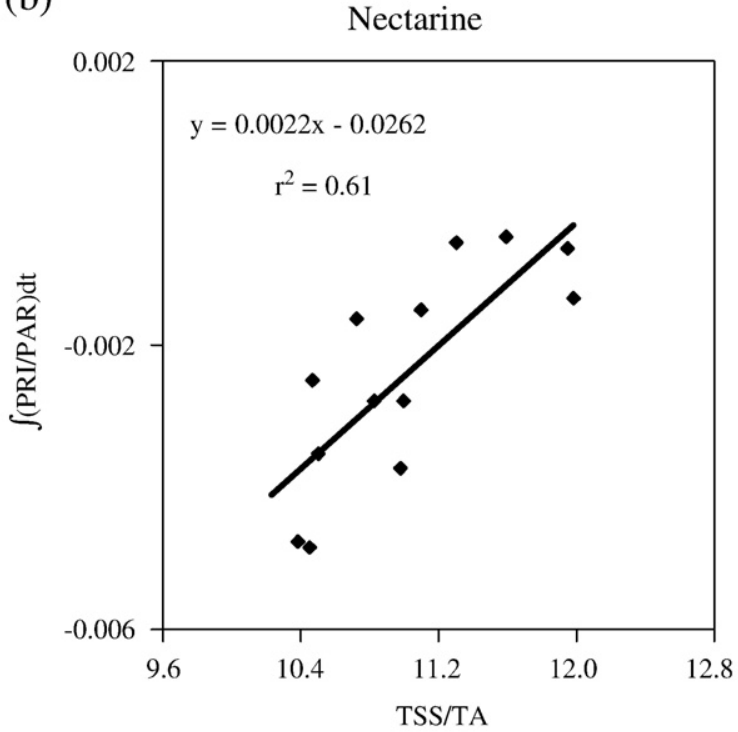

(d)

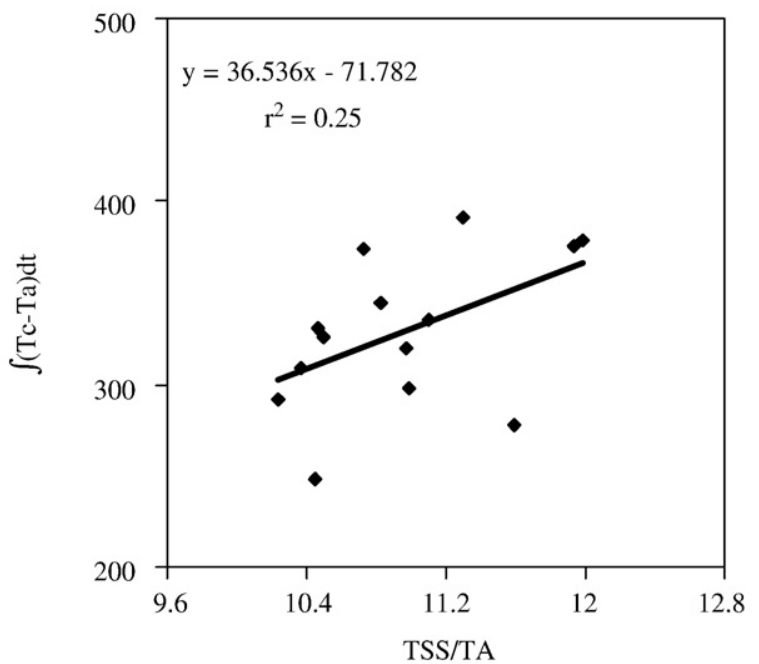

Fig. 7. Integral of PRI/PAR and $T_{\mathrm{c}}-T_{\mathrm{a}}$ from imagery for Stages II and III of fruit growth versus the fruit quality ratio, TSS/TA for peach (a and c) and nectarine (b and d).

measured at harvest for the nectarine experiment. The higher values of EPS, obtained from trees under full irrigation, corresponded to lower values of TSS/TA found in fruits of that treatment. Previous studies on peach have demonstrated the inverse relationship between tree water status at Stage II of fruit growth and the ratio TSS/TA (calculations from data published by Crisosto et al., 1994; Gelly et al., 2003).

In the orange orchard experiment, one treatment was subjected to sustained but mild deficit irrigation throughout the irrigation season. Measurements of PRI, NDVI, SR, TCARI/OSAVI and temperature extracted from imagery were related to fruit parameters. The relationships of fruit quality parameters (TSS, TA, TSS/TA and fruit size) with the physiological and structural indices are listed in Table 3. PRI showed the highest correlation with TA and TSS/TA, which are considered important indicators of fruit quality. On the contrary, crown temperature was not associated with any of the quality parameters, with one exception (fruit size; $r^{2}=0.47$ ). This is consistent with the stem water potential measurements, which indicated no significant differences between the deficit irrigation treatment and the control. Consequently, crown temperature differences between the two treatments were hardly detectable. The PRI image on the orange orchard was acquired during the stage of rapid fruit growth. Fig. 5 shows the relationship of TSS/TA with: a) PRI; b) temperature; c) NDVI; and, d) TCARI/OSAVI. Crown PRI correlated reasonably well with TSS/TA $\left(r^{2}=0.50\right)$, while other indicators of water stress, such as temperature, structural indices such as NDVI and SR, and an index related to chlorophyll content TCARI/OSAVI were not related to TSS/TA, (coefficients of determination of 0, 0.16, 0.17 and 0.18 , respectively; Fig. 5 and Table 3 ). Although canopy temperature is a reliable remote sensing water stress indicator (Jackson et al., 1977), crown temperature values should be related to the instantaneous transpiration rate at the time of image acquisition. By contrast, crown PRI values reflect physiological processes related to photosynthesis as affected by water stress. Because fruit quality is more tied to photosynthesis and carbon metabolism, PRI may be a better estimator of fruit quality than other established water stress indicators that are related directly to transpiration such as crown temperature.

In the peach experiment, the time courses of water deficits and recovery were monitored by measuring crown PRI from imagery and SWP in the field. The water-stressed trees showed lower SWP and higher crown PRI values (representing stress conditions) than the control trees. Fig. 6 shows the time-series of PRI/PAR and the normalized SWP values (values divided by those of the control 
(a)

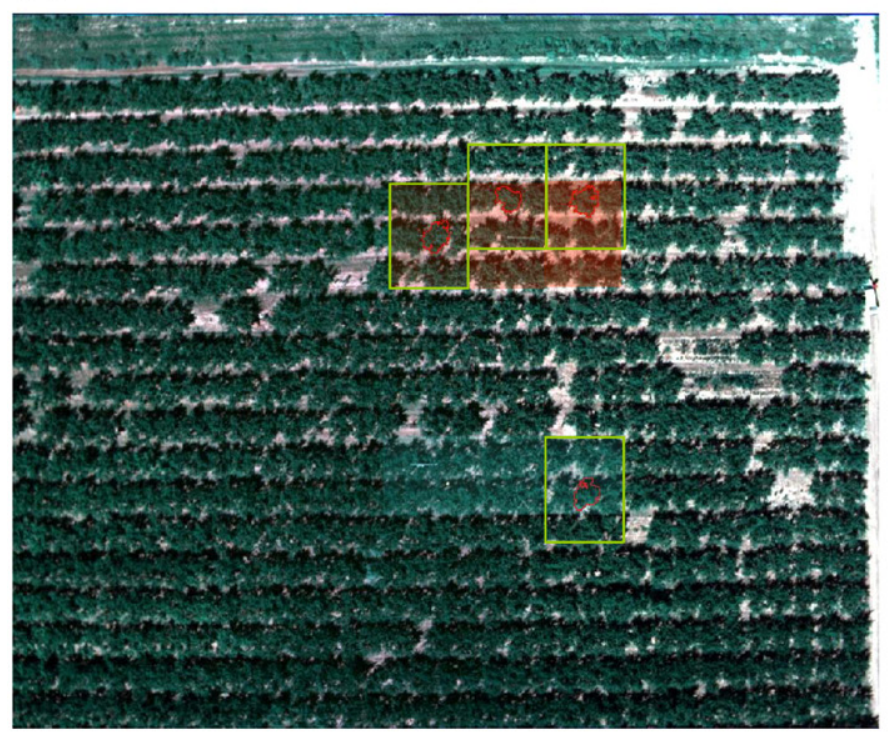

(b)

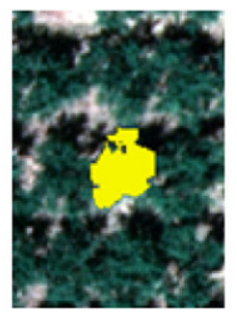

(f)

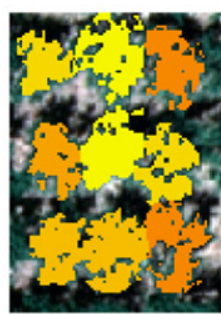

(c)

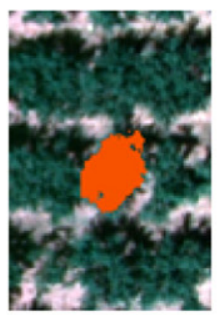

(g)

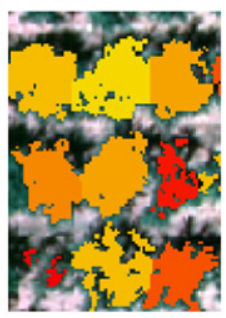

(d)

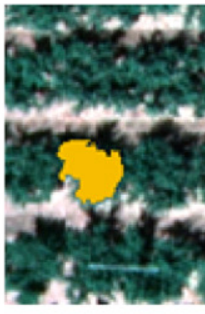

(h)

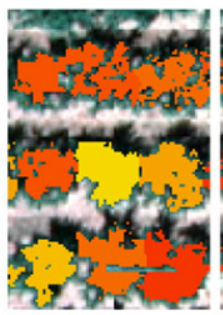

(e)

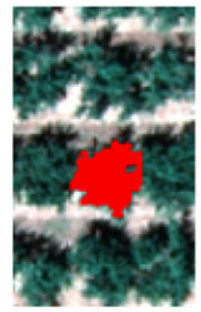

(i)

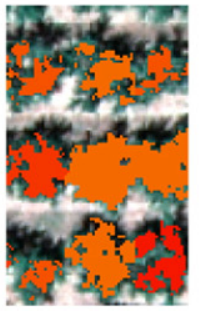

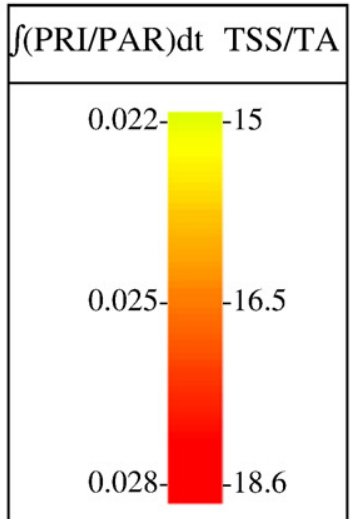

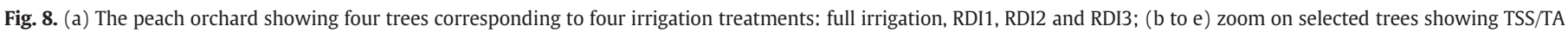
values; ( $f$ to $\mathrm{i}$ ) zoom on selected and surrounding trees showing the integral of PRI/PAR.

treatment). During the water deficit period that corresponded to Stage II of fruit growth, the values of PRI/PAR for the three deficit irrigation treatments were similar and higher than the control values, indicating water stress (Fig. 6). Similarly, the SWP of those treatments were lower than that of the fully-irrigated treatment. As the rapid growth or stage III of fruit growth began in 4 July ("Irrigation 1"), the RDI-1 treatment was re-irrigated until its SWP recovered to control values, a process that took 5 days. One week later ("Irrigation 2 "), the RDI-2 treatment was re-irrigated, and the PRI/PAR for both RDI- 1 and RDI-2 treatments fell below the control values (Fig. 6) showing recovery of water status. Equally, SWP values recovered in RDI-1 and RDI-2 until they reached the values of the fully-irrigated treatment, although the RDI-2 treatment took ten days to recover (Fig. 6). The RDI-3 treatment entered the recovery phase at "Irrigation 3"; both the SWP and PRI/PAR records showed that recovery in this treatment occurred after 13 days, taking longer to recover from the more severe water stress than the other two RDI treatments. The results of Fig. 6 clearly demonstrate that the PRI/PAR measurements tracked the evolution of tree water status in the various treatments.

In the peach experiment, the variation in irrigation regimes with time indicated that a single measurement of PRI could not glean stress history. Therefore, it was necessary to use a time-series of data acquired during fruit growth to accurately describe the different treatments. Table 4 presents the results of analyzing the indices timeseries (computed over Stages II and III of peach and nectarine fruit growth) against the parameters TSS, TA, TSS/TA and fruit size. Again, the ratio TSS/TA was best correlated with the integral of PRI/PAR for peach and nectarine trees. Fig. 7 shows an independent analysis of the two water stress indicators: PRI/PAR and $T_{\mathrm{c}}-T_{\mathrm{a}}$. Fig. 7a and $\mathrm{c}$ show the relationship of the integral of PRI/PAR and $T_{\mathrm{c}}-T_{\mathrm{a}}$ with TSS/TA for 
peach, and Fig. $7 \mathrm{~b}$ and $\mathrm{d}$ show the same for nectarines. The correlation of TSS/TA with the integral of PRI/PAR calculated for every single crown using a set of ten images taken in different days yielded linear relationships of $r^{2}=0.72$ for the peach tree experiment, and $r^{2}=0.61$ for the nectarine orchard (Fig. 7a and b, respectively). By contrast, relationships between the integral of $T_{\mathrm{c}}-T_{\mathrm{a}}$ with TSS/TA, yielded much lower linear relationships for peach $\left(r^{2}=0.21\right)$ and nectarines $\left(r^{2}=0.25\right)$ (Fig. 7c and d). A possible explanation for the difference in behaviour between PRI and $T_{\mathrm{c}}-T_{\mathrm{a}}$ lies in the changes in carbon partitioning in response to mild water deficits. It has been shown that deficit irrigation alters the distribution of carbon, increasing the allocation to fruits (Fereres and Soriano, 2007). Mild water deficits that hardly would affect transpiration (and hence $T_{\mathrm{c}}-T_{\mathrm{a}}$ ) may have some effects on carbon metabolism that are reflected in the light reactions of photosynthesis and are detected by PRI measurements.

The effect of water stress on fruit size, an important commercial parameter (Guardiola \& García-Luis, 2000), was studied in peach and nectarine using multispectral imagery acquired during Stage III of exponential fruit growth, when the absence of water stress is critical (Génard \& Huguet, 1996). PRI/PAR time-series computed over Stage III of fruit growth correlated well with fruit size at harvest $\left(r^{2}=0.51\right.$, data not shown), while the correlation of $T_{\mathrm{c}}-T_{\mathrm{a}}$ time-series yielded a much smaller coefficient of determination $\left(r^{2}=0.15\right)$. Fig. 8 presents an overview of the peach experiment with the different treatments and a zoom on four of the monitored trees, each of them corresponding to a different irrigation schedule: Full-irrigated, RDI1, RDI-2 and RDI-3 (Fig. 8a). Fig. 8b to e show the ratio TSS/TA for the four trees. In Fig. $8 \mathrm{f}$ to $\mathrm{i}$, the integral of PRI/PAR is shown for each of the selected and surrounding trees, demonstrating that the variability among trees of the water stress-integral within-treatments may be detected using an image-based methodology. The values of the integral of PRI/PAR and TSS/TA represented using the same color code, appear the same for the four selected trees, demonstrating that the detection of fruit quality is possible using the time-series of PRI/PAR. Moreover, the use of remote sensing for the assessment of fruit quality parameters permits the spatial characterization of an entire orchard.

The assessment of the influence of the imagery spatial resolution on PRI was studied using image data and radiative transfer modelling. The performance of the integral of PRI/PAR for different spatial resolutions was assessed using data from imagery. First, only the reflectance extracted from pure crowns was used (Fig. 9a), and then the reflectance extracted from aggregated pixels, including soil, shadows and crowns (Fig. 9b). The use of high spatial resolution imagery (zoom shown in Fig. 9c) allowed the classification of the crown into sunlit vegetation pixels and shadowed vegetation pixels. Fig. 9d presents an example of a supervised maximum likelihood classification in which within-crown sunlit vegetation and shadows can be identified. When the integral of PRI/PAR is calculated using pure crown reflectance (Fig. 10), the integral at crown scale, as a function of the EPS along the fruit growth, is well correlated with the TSS/TA ratio $\left(r^{2}=0.72\right.$, Fig. 10a). The integral of PRI/PAR extracted from pure crown pixels (i.e., high spatial resolution) versus the integral of PRI/PAR extracted from aggregated pixels where there is crown, soil and shadows (low-spatial resolution) yielded a very low association $\left(r^{2}=0.06\right.$, Fig. 10b). The lack of relationship when scene components are aggregated in a mixed pixel suggests that the PRI vs. EPS relationship is lost when pure sunlit crowns are not selected. In fact, the relationship of the integral of "low-spatial resolution" PRI with TSS/TA yielded a coefficient of determination of 0.25 (Fig. 10c), versus the $r^{2}=0.72$ when using high spatial resolution PRI. The results of modelling PRI for pure crown and aggregated pixels suggest a large influence of soil and shadows on the index (Fig. 11), which prevents detecting the physiological responses to mild water stress levels. Aggregated PRI values extracted from the full reflectance scene differ greatly from pure crown PRI values as vegetation coverage decreases, increasing the proportion of soil and shadowed back- ground in the aggregated pixel from $100 \%$ to $10 \%$ vegetation cover. The effects on the index as a function of three soil types (spectra from Fig. 2) were assessed. Dark soils showed a higher influence on aggregated PRI values (see the separation from the 1:1 line), even for high percentage vegetation coverage (Fig. 11). The dark soil spectrum is low and flat in comparison with the two other soil spectra used, then the influence on PRI is higher than the influence of soils with steeper spectra. The possible errors using low-resolution imagery are presented in Fig. 12. The error bars in Fig. 12b represent the variability of the PRI value for an aggregated pixel depending on the soil type. These modelling results emphasize the need for high spatial resolution imagery to reproduce the results obtained in this study, as medium resolution PRI imagery would be heavily affected by background and shadow components, greatly reducing the sensitivity to physiological indicators of stress, such as PRI. Future developments in this field may focus on minimizing background effects in order to use our methodology with lower spatial resolution imagery. One approach could be the use of a soil-adjusted vegetation index to deal with variable backgrounds. The first soil-adjusted vegetation index presented was SAVI (Huete, 1988). Subsequently, additional indices have been proposed such as TSAVI (Baret \& Guyot, 1991), MSAVI (Qi et al., 1994), OSAVI (Rondeaux et al., 1996), and GESAVI (Gillabert et al., 2002), among others. Other authors have successfully transformed indices using soil-adjusted lines to minimize soil influence on spectral reflectance (Haboudane et al., 2002). Use of (a)

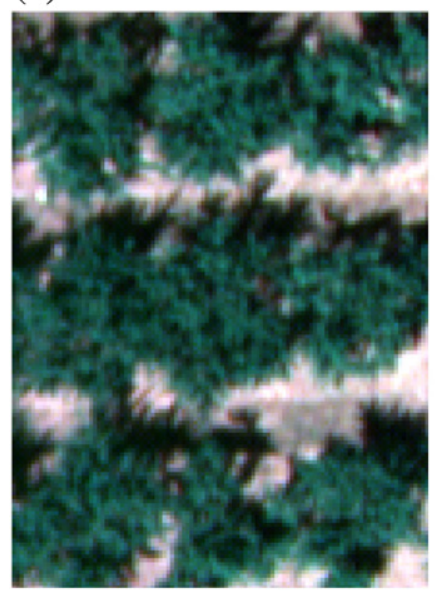

(c)

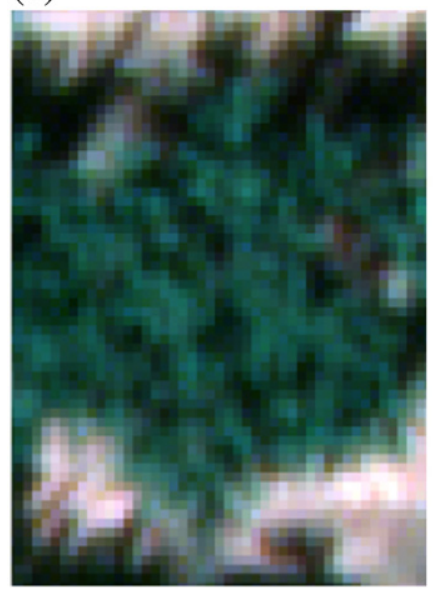

(b)

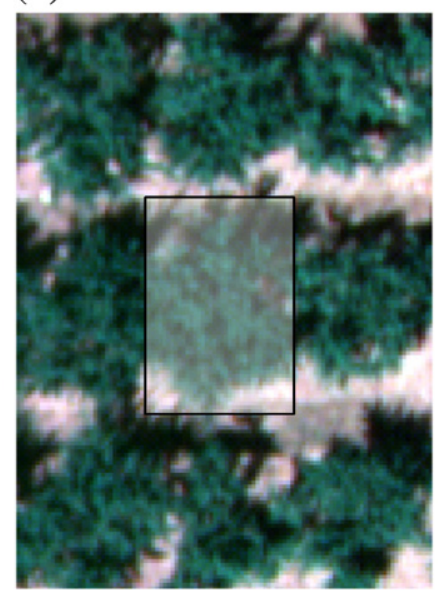

(d)

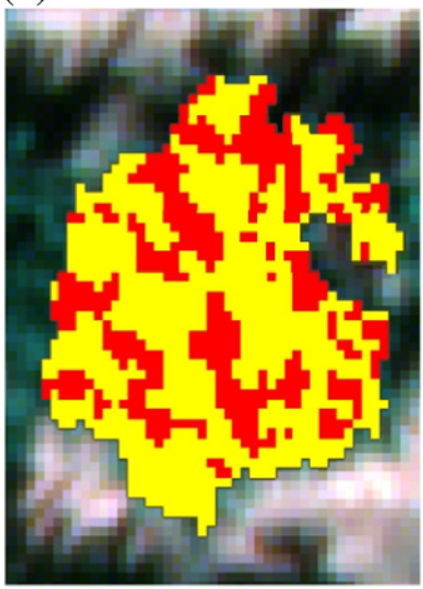

Fig. 9. (a) Zoom on an image from the peach study area; (b and c) area corresponding to aggregated crown, soil and shadows; (d) high spatial resolution imagery enabling within-crown separation of sunlit (yellow) and shaded vegetation (red). 

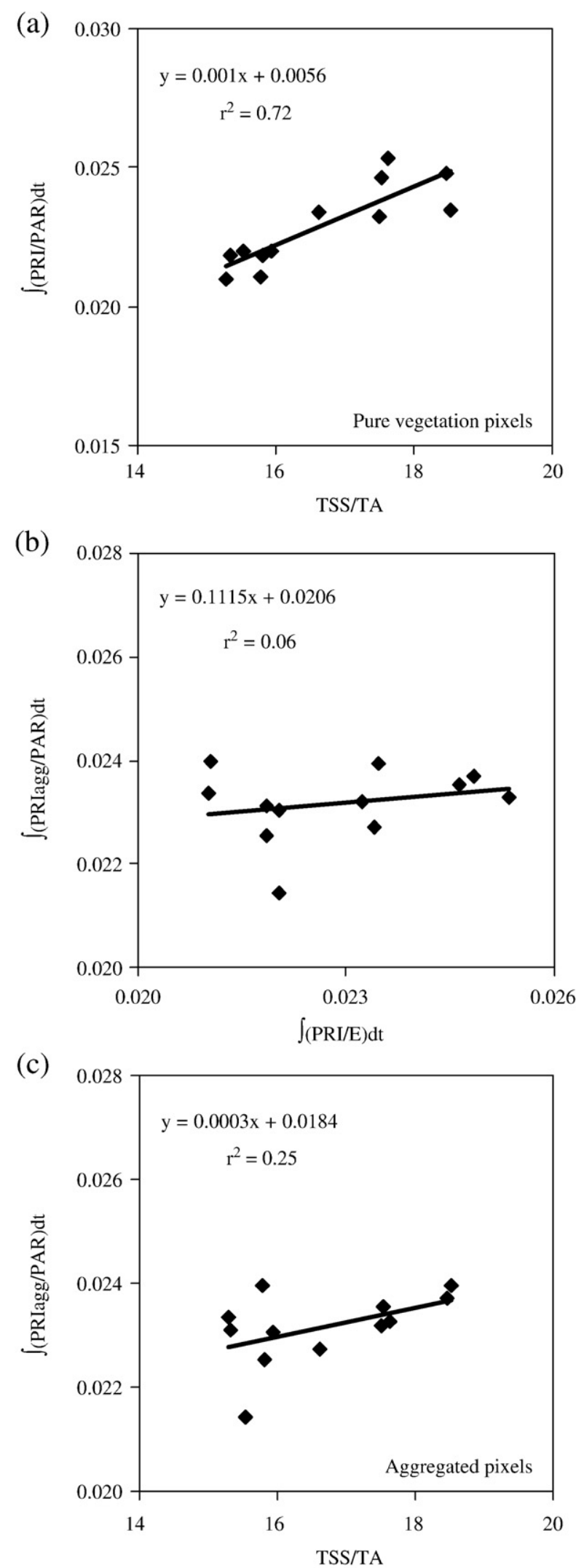

Fig. 10. Relationship between the integral of PRI/PAR extracted from pure crowns and the fruit quality ratio, TSS/TA (a); relationship between the integral of PRI/PAR extracted from pure vegetation spectra vs the integral of PRI/PAR of aggregated crown, soil and shadows (b); relationship between the integral of PRI/PAR for aggregated crown, soil and shadows with TSS/TA (c).

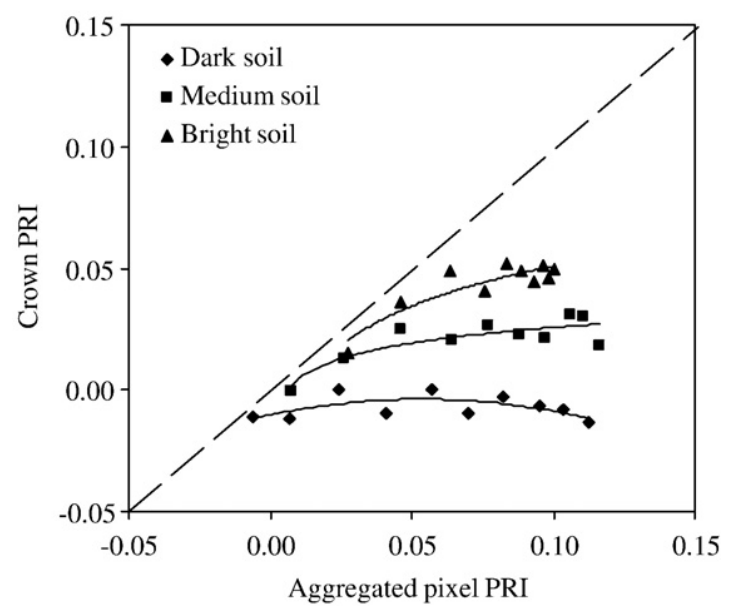

Fig. 11. Pure crown PRI values extracted from radiative transfer simulation using the 3D forest light interaction model (FLIGHT) versus aggregated PRI including crown, soil and shadows for vegetation cover ranging from $100 \%$ to $10 \%$ for three backgrounds. Leaf input parameters were $N=1.6, C_{\mathrm{ab}}=40 \mu \mathrm{g} / \mathrm{cm}^{2}, C_{\mathrm{w}}=0.015, C_{\mathrm{m}}=0.015$ and $C_{\mathrm{s}}=0$, canopy input parameters were $\mathrm{LAD}=$ spherical, crown $\mathrm{LAI}=2.5$, solar zenith $=23^{\circ}$ and solar azimuth $=124^{\circ}$.

(a)
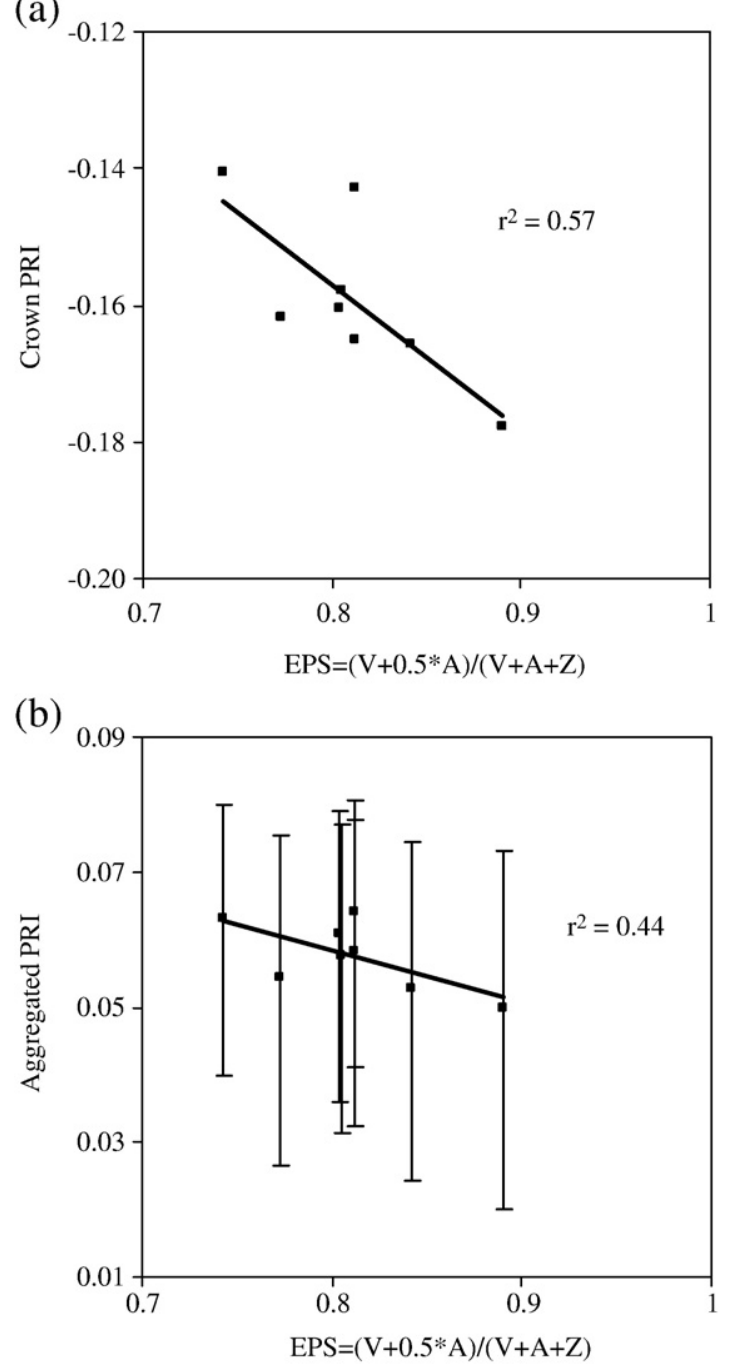

Fig. 12. (a) Relationship between EPS and pure crown PRI for peach trees; (b) relationship between EPS and PRI from aggregated pixels including different backgrounds. The error bars are function of the maximum and minimum scene PRI corresponding to each EPS value. 
the above-mentioned approaches may adapt this methodology to lower spatial resolution imagery.

\section{Conclusions}

This study demonstrates the link between the epoxidation state of the xanthophyll cycle and the fruit quality measured in orchards under different irrigation regimes, enabling the remote detection of fruit quality as a function of water stress using high-resolution airborne PRI. The PRI index measured at leaf scale was in agreement with the epoxidation state of the xanthophyll cycle calculated from destructive sampling. In addition, the airborne image-derived PRI values calculated from pure crown reflectance were also in agreement with xanthophyll EPS measured on the same trees. Moreover, the time-series of airborne PRI normalized by the incoming PAR at the time of imagery acquisition (PRI/PAR) matched the changes in tree water status as affected by the different irrigation regimes. In an orange orchard under sustained deficit irrigation, crown PRI calculated from the airborne imagery acquired during the fruit growth was well related to fruit quality. For peach and nectarine orchards subjected to period of water stress and recovery a methodology was applied that used the time-series of PRI/PAR to assess the fruit quality responses of the different stressed treatments.

Although the high-resolution PRI time-series exhibited a good relationship with fruit quality, crown airborne temperature acquired over the same trees, the established method for remote sensing of water stress, did not yield comparable results and did not correlate with fruit quality. This highlights the advantage of the PRI as a water stress indicator related to other physiological processes and not only to transpiration, for the assessment of fruit quality. Finally, the use of high spatial resolution imagery appears critical for a tight relationship between PRI and EPS, and therefore for assessing fruit quality from airborne PRI measurements. A radiative transfer simulation study demonstrated the influence of soil and shadows on canopy reflectance used to calculate PRI on aggregated pixels, suggesting the critical effects that soil variability has in the computation of the PRI index in discontinuous orchard canopies. This work demonstrates the feasibility for assessing fruit quality in orchards using PRI when high spatial resolution remote sensing imagery is used $(20 \mathrm{~cm}$ in the present study) as opposed to using lower spatial resolutions where the pixels represent a mixture of shadows, vegetation and soil. The practical implications of this approach to optimize harvest operations and maximize revenues in horticultural crops based on field segmentation as a function of fruit quality may be substantial.

\section{Acknowledgements}

Financial support from the Spanish Ministry of Science and Innovation (MCI) for the projects AGL2005-04049, EXPLORA-INGENIO AGL2006-26038-E/AGR, CONSOLIDER CSD2006-67, and AGL200301468, and from Gobierno de Aragón (group A03) is gratefully acknowledged, and support in-kind provided by Bioiberica through the project PETRI PET2005-0616. Technical support from UAV Navigation and Tetracam Inc. is also acknowledged. M. Medina, C. Ruz, R. Gutierrez, A. Vera, D. Notario, I. Calatrava and M. Ruiz Bernier are acknowledged for measurements and technical support in field and airborne campaigns. The Plant Stress Physiology Group of the Experimental Station of Aula Dei (CSIC) in Zaragoza is acknowledged for technical support on the leaf pigment extraction and quantification.

\section{References}

Abadía, A., \& Abadía, J. (1993). Iron and plant pigments. In L. L. Barton \& B. C. Hemming (Eds.), Iron chelation in plants and soil microorganisms (pp. 327-344). San Diego: Academic.

Asner, G. P., Carlson, K. M., \& Martin, R. E. (2005). Substrate age and precipitation effects on Hawaiian forest canopies from spaceborne imaging spectroscopy. Remote Sensing of Environment, 98, 457-467.
Asrar, G., Kanemasu, E. T., Jackson, R. D., \& Pinter, J. R. (1985). Estimation of total aboveground phytomass production using remotely sensed data. Remote Sensing of Environment, 17, 211-220.

Baeza, P., Sánchez-de-Miguel, P., Centeno, A., Junquera, P., Linares, R., \& Lissarrague, J. R. (2007). Water relations between leaf water potential, photosynthesis and agronomic vine response as a tool for establishing thresholds in irrigation scheduling. Scientia Horticulturae, 114, 151-158.

Baret, F., \& Guyot, G. (1991). Potentials and limits of vegetation indices for LAI and PAR assessment. Remote Sensing of Environment, 35, 161-173.

Barton, C. V. M., \& North, P. R. J. (2001). Remote sensing of canopy light use efficiency using the photochemical reflectance index. Model and analysis. Remote Sensing of Environment, 78(264), 273.

Berni, J. A. J., Zarco-Tejada, P. J., Suarez, L., \& Fereres, E. (2009). Thermal and narrowband multispectral remote sensing for vegetation monitoring from an unmanned aerial vehicle. IEEE Transactions on Geoscience and Remote Sensing, 47, 722-738.

Chalmers, D. J., Mitchell, P. D., \& Van Heek, L. (1981). Control of peach tree growth and productivity by regulated water supply, tree density and summer pruning. Journal of the American Society of Horticultural Sciences, 106, 307-312.

Cohen, Y., Alchanatis, V., Meron, M., Saranga, Y., \& Tsipris, J. (2005). Estimation of leaf potential by thermal imagery and spatial analysis. Journal of Experimental Botany, $56,1843-1852$.

Crisosto, C. H., Crisosto, G. M., Echeverria, G., \& Puy, J. (2006). Segregation of peach and nectarine (Prunus persica (L.) Batsch) cultivars according to their organoleptic characteristics. Postharvest Biology and Technology, 39, 10-18.

Crisosto, C. H., Johnson, R. S., Luza, J. G., \& Crisosto, G. M. (1994). Irrigation regimes affect fruit soluble solids concentration and rate of water loss of 'O'Henry' peaches. Horticultural Sciences, 29, 1169-1171.

Dobrowsky, S. Z., Pushnik, J. C., Zarco-Tejada, P. J., \& Ustin, S. L. (2005). Simple reflectance indices track heat and water stress-induced changes in steady-state chlorophyll fluorescence at the canopy scale. Remote Sensing of Environment, 97, 403-414.

Drolet, G. G., Huemmrich, K. F., Hall, F. G., Middleton, E. M., Black, T. A., Barr, A. G., \& Margolis, H. A. (2005). A MODIS-derived photochemical reflectance index to detect inter-annual variations in the photosynthetic light-use efficiency of a boreal deciduous forest. Remote Sensing of Environment, 98, 212-224.

Evain, S., Flexas, J., \& Moya, I. (2004). A new instrument for passive remote sensing: 2. Measurement of leaf and canopy reflectance changes at $531 \mathrm{~nm}$ and their relationship with photosynthesis and chlorophyll fluorescence. Remote Sensing of Environment, 91, 175-185.

Fereres, E., \& Soriano, M. (2007). Deficit irrigation for reducing agricultural water use. Journal of Experimental Botany, 58, 147-159.

Filella, I., Amaro, T., Araus, J. L., \& Peñuelas, J. (1996). Relationship between photosynthetic radiation-use efficiency of barley canopies and the photochemical reflectance index (PRI). Physiologia Plantarum, 96, 211-216.

Fuentes, D. A., Gamon, J. A., Cheng, Y., Claudio, H. C., Qiu, H. L., Mao, Z., Sims, D. A., Rahman, A. F., Oechel, W., \& Luo, H. (2006). Mapping carbon and water vapour fluxes in a chaparral ecosystem using vegetation indices derived from AVIRIS. Remote Sensing of Environment, 103, 312-323.

Gamon, J. A., Peñuelas, J., \& Field, C. B. (1992). A narrow-wave band spectral index that track diurnal changes in photosynthetic efficiency. Remote Sensing of Environment, $41,35-44$.

Gamon, J. A., Serrano, L., \& Surfus, J. S. (1997). The photochemical reflectance index: An optical indicator of photosynthetic radiation use efficiency across species, functional types, and nutrient levels. Oecologia, 112, 492-501.

Gelly, M., Recasens, I., Mata, M., Arbones, A., Rufat, J., Girona, J., \& Marsal, J. (2003). Effects of water deficit during stage II of peach fruit development and postharvest on fruit quality and ethylene production. Journal of Horticultural Science $\mathcal{\sigma}^{\prime}$ Biotechnology, 78, 324-330.

Génard, M., \& Huguet, J. G. (1996). Modeling the response of peach fruit growth to water stress. Tree Physiology, 16, 407-415.

Gillabert, M. A., González-Piqueras, J., García-Haro, F. J., \& Meliá, J. (2002). A generalized soil-adjusted vegetation index. (2002). Remote Sensing of Environment, 82, 303-310.

Ginestar, C., \& Castel, J. R. (1996). Response of young 'Clementine' citrus trees to water stress during different phonological periods. Journal of Horticultural Science, 71(4), $551-559$.

Girona, J. (2002). Regulated deficit irrigation in peach. A global analysis. Acta Horticulturae, 592, 335-342.

Girona, J., Mata, M., Arbonès, A., Alegre, S., Rufat, J., \& Marsal, J. (2003). Peach tree response to single and combined regulated deficit irrigation regimes under swallow soils. Journal of the American Society of Horticultural Sciences, 128, 432-440.

González-Altozano, P., \& Castel, J. R. (1999). Regulated déficit irrigation in “Clementina de Nules" citrus tree. I. Yield and fruit quality effects. Journal of Horticultural Science and Biotechnology, 74, 706-713.

Guardiola, J. L., \& García-Luis, A. (2000). Increasing fruit size in citrus. Thinning and stimulation of fruit growth. Plant Growth Regulation, 31, 121-132.

Guo, J., \& Trotter, C. M. (2004). Estimating photosynthetic light-use efficiency using the photochemical reflectance index: Variations among species. Functional Plant Biology, 31, 255-565.

Guo, J., Trotter, C. M., \& Newton, P. C. D. (2006). Initial observations of increased requirements for light-energy dissipation in ryegrass (Lolium perenne) when source/sink ratios become high at a naturally grazed Free Air $\mathrm{CO}_{2}$ Enrichment (FACE) site. Functional Plant Biology, 33, 1045-1053.

Haboudane, D, Miller, J. R, Tremblay, N. Zarco-Tejada, P. J, \& Dextraze, L (2002). Integrated narrow-band vegetation indices for prediction of crop chlorophyll content for application to precision agriculture. Remote Sensing of Environment, 84, 416-426.

Huete, A. R. (1988). A soil-adjusted vegetation index (SAVI). Remote Sensing of Environment, 25, 295-309. 
Idso, S. B. (1982). Humidity measurement by Infrared Thermometry. (1982). Remote Sensing of Environment, 12, 87-91.

Idso, S. B. (1982). Non-water-stressed baselines: A key to measuring and interpreting plant water stress. Agricultural Meteorology, 27, 59-70.

Idso, S. B., Jackson, R. D., Pinter, P. J., Reginato, R. J., \& Hatfield, J. L. (1981). Normalizing the stress-degree-day parameter for environmental variability. Agricultural and Forest Meteorology, 24, 45-55.

Jackson, R. D., Idso, S. B., Reginato, R. J., \& Ehrier, W. L. (1977). Crop temperature reveals stress. Crop Soils, 29, 10-13.

Jackson, R. D., Idso, S. B., Reginato, R. J., \& Pinter, P. J., Jr. (1981). Canopy temperature as a crop water stress indicator. Water Resources Research, 17, 1133-1138.

Jackson, R. D., Slater, P. N., \& Pinter, P. J., Jr. (1983). Discrimination of growth and water stress in wheat by various vegetation indices through clear and turbid atmospheres. Remote Sensing of Environment, 13, 187-208.

Jacquemoud, S., \& Baret, F. (1990). PROSPECT: A model of leaf optical properties spectra. Remote Sensing of Environment, 34, 75-91.

Johnson, L. F., Bosch, D. F., Williams, D. C., \& Lobitz, B. M. (2001). Remote sensing of vineyard management zones: Implications for wine quality. Applied Engineering in Agriculture, 17, 557-560.

Johnson, L. F., Roczen, D. E., Youkhana, S. K., Nemani, R. R., \& Bosch, D. F. (2003). Mapping vineyard leaf area with multispectral satellite imagery. Computers and Electronics in Agriculture, 38, 33-44.

Kriston-Vizi, J., Umeda, M., \& Miyamoto, K. (2008). Assessment of the water stress status of mandarin and peach canopies using visible multispectral imagery. Biosystems Engineering, 100, 338-345.

Lamb, D. W., Weedom, M. M., \& Ramley, R. G. V. (2004). Using remote sensing to predict grape phenolics and colour at harvest in a Cabernet Sauvignon vineyard: Timing observations against vine phenology and optimising image resolution. Australian Journal of Grape and Wine Research, 10, 46-54.

Larbi, A., Abadía, A., Morales, F., \& Abadía, J. (2004). Fe resupply to Fe-deficient sugar beet plants leads to rapid changes in the violaxanthin cycle and other photosynthetic characteristics without significant de novo chlorophyll synthesis. Photosynthesis Research, 79, 59-69.

Leinonen, I., \& Jones, H. G. (2004). Combining thermal and visible imagery for stimulating canopy temperature and identifying plant stress. Journal of Experimental Botany, 55, 1423-1431.

Marsal, J., \& Girona, J. (1997). Relationship between leaf water potential and gas exchange activity at different phonological stages and fruit loads in peach trees. Journal of the American Society of Horticultural Sciences, 122, 415-421.

Mills, T. M., Behboudian, M. H., \& Tan, P. Y. (1994). Plant water status and fruit quality in "Braeburn" apples. Horticultural Science, 29, 1274-1278.

Myers, B. J. (1988). Water stress integral - A link between short-term stress and longterm growth. Tree Physiology, 4, 315-323.

Nakaji, T., Oguma, H., \& Fujinuma, Y. (2006). Seasonal changes in the relationship between photochemical reflectance index and photosynthetic light use efficiency of Japanese larch needles. International Journal of Remote Sensing, 27, 493-509.

Nichol, C. J., Huemmrich, K. F., Black, T. A., Jarvis, P. G., Walthall, J. G., \& Hall, F. G. (2000). Remote sensing of photosynthetic-light-use efficiency of boreal forest. Agricultural and Forest Meteorology, 101, 131-142.

Nichol, C. J., Lloyd, J., Shibistova, O., Arneth, A., Röser, C., Knohl, A., Matsubara, S., \& Grace, J. (2002). Remote sensing of photosynthetic-light-use-efficiency of a Siberian boreal forest. Tellus, 54B, 677-687.
Nichol, C. J., Rascher, U., Matsubara, S., \& Osmond, B. (2006). Assessing photosynthetic efficiency in an experimental mangrove canopy using remote sensing and chlorophyll fluorescence. Trees, 20, 9-15.

North, P. R. J. (1996). Three-dimensional forest light interaction model using a Montecarlo method. IEEE Transactions on Geosciences and Remote Sensing, 34, 946-956.

Peguero-Pina, J.J., Morales, F., Flexas, J., Gil-Pelegrín, E., \& Moya, I. (2008). Photochemistry, remotely sensed physiological reflectance index and de-epoxidation state of xanthophyll cycle in Quercus coccifera under intense drought. Oecologia, 156, 1-11.

Qi, J., Chehbouni, Al, Huete, A. R., Kerr, Y. H., \& Sorooshian, S. (1994). A modified soil adjusted vegetation index (MSAVI). Remote Sensing of Environment, 48, 119-126.

Rondeaux, G., Steven, M., \& Baret, F. (1996). Optimization of soil-adjusted vegetation indices. Remote Sensing of Environment, 55, 95-107.

Rouse, J.W., Haas, R.H., Schell, J.A., Deering, D.W. \& Harlan, J.C. (1974). Monitoring the vernal advancements and retrogradation of natural vegetation. in Nasa/Gsfc Final Report (ed. MD, U.G.) p. 371.

Sepulcre-Cantó, G., Zarco-Tejada, P. J., Jiménez-Muñoz, J. C., Sobrino, J. A., Soriano, M. A. Fereres, E., Vega, V., \& Pastor, M. (2007). Monitoring yield and fruit quality parameters in open-canopy tree crops under water stress. Implications for ASTER. Remote Sensing of Environment, 107, 455-470.

Sepulcre-Cantó, G., Zarco-Tejada, P. J., Sobrino, J. A., Berni, J. A. J., Jiménez Muñoz, J. C., \& Gastellu-Etchegorry, J. P. (2009). Detecting water status in open canopies with thermal ASTER imagery and DART radiative transfer simulation. Agricultural and Forest Meteorology, 149, 962-975.

Serrano, L., \& Peñuelas, J. (2005). Assessing forest structure and function from spectral transmittance measurements: A case study in a Mediterranean Holm oak forest. Tree Physiology, 25, 67-74.

Sims, D. A., Luo, H., Hastings, S., Oechel, W. C., Rahman, A. F., \& Gamon, J. A. (2006) Parallel adjustment in vegetation greenness and ecosystem $\mathrm{CO}_{2}$ exchange in response to drought in a Southern California chaparral ecosystem. Remote Sensing of Environment, 103, 289-303.

Strachan, I. B., Pattey, E., \& Boisvert, J. B. (2002). Impact of nitrogen and environmental conditions on corn as detected by hyperspectral reflectance. Remote Sensing of Environment, 80, 213-224.

Suárez, L., Zarco-Tejada, P. J., Berni, J. A. J., González-Dugo, V., \& Fereres, E. (2009) Modelling PRI for water stress detection using radiative transfer models. Remote Sensing of Environment, 113, 730-744.

Suárez, L., Zarco-Tejada, P. J., Sepulcre-Cantó, G., Pérez-Priego, O., Miller, J. R., JiménezMuñoz, J. C., \& Sobrino, J. (2008). Assessing canopy PRI for water stress detection with diurnal airborne imagery. Remote Sensing of Environment, 112, 560-575.

Thayer, S. S., \& Björkman, O. (1990). Leaf xanthophyll content and composition in sun and shade determined by HPLC. Photosynthesis Research, 23, 331-343.

Thenot, F., Méthy, M., \& Winkel, T. (2002). The Photochemical Reflectance Index (PRI) as a water-stress index. International Journal of Remote Sensing, 23, 5135-5139.

Trotter, G. M., Whitehead, D., \& Pinkney, E. J. (2002). The photochemical reflectance index as a measure of photosynthetic light use efficiency for plants with varying foliar nitrogen contents. International Journal of Remote Sensing, 23, 1207-1212.

Veihmeyer, F. J. (1927). Some factors affecting the irrigation requirements of deciduous orchards. Hilgardia, 2, 125-284. 